\title{
A $\beta_{\mathrm{IV}}$-spectrin/CaMKII signaling complex is essential for membrane excitability in mice
}

\author{
Thomas J. Hund, ${ }^{1}$ Olha M. Koval, ${ }^{1}$ Jingdong Li, ${ }^{1}$ Patrick J. Wright, ${ }^{1}$ Lan Qian, ${ }^{1}$ \\ Jedidiah S. Snyder, ${ }^{1}$ Hjalti Gudmundsson, ${ }^{1}$ Crystal F. Kline, ${ }^{1}$ Nathan P. Davidson, ${ }^{1}$ \\ Natalia Cardona, ${ }^{1}$ Matthew N. Rasband, ${ }^{2}$ Mark E. Anderson, ${ }^{1,3}$ and Peter J. Mohler ${ }^{1,3}$ \\ ${ }^{1}$ Department of Internal Medicine, Division of Cardiovascular Medicine, University of lowa Carver College of Medicine, lowa City, Iowa, USA. \\ 2Department of Neuroscience and Department of Molecular and Cellular Biology, Baylor College of Medicine, Houston, Texas, USA. \\ 3Department of Molecular Physiology and Biophysics, University of lowa Carver College of Medicine, lowa City, lowa, USA.
}

\begin{abstract}
Ion channel function is fundamental to the existence of life. In metazoans, the coordinate activities of voltagegated $\mathrm{Na}^{+}$channels underlie cellular excitability and control neuronal communication, cardiac excitationcontraction coupling, and skeletal muscle function. However, despite decades of research and linkage of $\mathrm{Na}^{+}$ channel dysfunction with arrhythmia, epilepsy, and myotonia, little progress has been made toward understanding the fundamental processes that regulate this family of proteins. Here, we have identified $\beta_{\mathrm{IV}}$-spectrin as a multifunctional regulatory platform for $\mathrm{Na}^{+}$channels in mice. We found that $\beta_{\mathrm{IV}}$-spectrin targeted critical structural and regulatory proteins to excitable membranes in the heart and brain. Animal models harboring mutant $\beta_{\mathrm{IV}}$-spectrin alleles displayed aberrant cellular excitability and whole animal physiology. Moreover, we identified a regulatory mechanism for $\mathrm{Na}^{+}$channels, via direct phosphorylation by $\beta_{\mathrm{IV}}$-spectrin-targeted calcium/calmodulin-dependent kinase II (CaMKII). Collectively, our data define an unexpected but indispensable molecular platform that determines membrane excitability in the mouse heart and brain.
\end{abstract}

\section{Introduction}

Membrane excitability requires the coordinate function of precisely synchronized signaling networks. Inherent to this precision are evolved molecular pathways that compartmentalize specific signaling molecules to ensure tight spatial and temporal coupling between plasma membrane and intracellular receptors, effector proteins, and target molecules. Members of the calcium/calmodulin-dependent protein kinase II (CaMKII) family - CaMKII $\alpha$, CaMKII $\beta$, CaMKII $\gamma$, and CaMKIII - are multifunctional serine/threonine kinases with critical roles in both excitable and non-excitable cells. CaMKII regulates diverse cellular functions, including ion channel biophysics, organelle transport, metabolism, and transcription, to modulate synaptic plasticity, cardiac excitation-contraction coupling, and hormone secretion (1-5). Furthermore, CaMKII signaling has been linked to specific disease phenotypes (5-13), including human heart failure and cognitive defects $(14,15)$, through its effects on a host of diverse and spatially distinct target proteins including ion channels and transporters (i.e., voltage-gated $\mathrm{Na}^{+}$channels; refs. 16-18), transcription factors, and cell death pathways (19-22). Finally, CaMKII inhibition has shown exciting promise for the treatment of excitable cell disease $(5,23-26)$. Collectively, these data strongly support the notion that local CaMKII/effector signaling nodes represent key cellular rheostats to translate local alterations in the cellular environment to global changes in membrane excitability and organism function.

Here, we define what we believe to be a novel signaling platform for the regulation of membrane excitability. Specifically, we identify $\beta_{\mathrm{IV}}$-spectrin, a key structural component required for ion channel clustering (including voltage-gated $\mathrm{Na}^{+}$channels) in the nervous system (27-34), as a multifunctional regulatory stage for

Conflict of interest: The authors have declared that no conflict of interest exists. Citation for this article: J Clin Invest. 2010;120(10):3508-3519. doi:10.1172/JCI43621.
$\mathrm{Na}^{+}$channel signaling in excitable cells. $\beta_{\mathrm{IV}}$-spectrin targets critical structural and regulatory proteins to excitable membranes in heart and brain, and animal models harboring mutant $\beta_{\mathrm{IV}}$-spectrin alleles display aberrant cellular excitability and whole-animal physiology. Here we show a fundamental, but unanticipated, requirement for $\beta_{\mathrm{IV}}$-spectrin-dependent targeting of CaMKII to a controlling phosphorylation site, S571, on the dominant cardiac $\mathrm{Na}^{+}$channel $\left(\mathrm{Na}_{\mathrm{v}} 1.5\right)$. Moreover, our findings provide evidence for a similar targeting and regulatory complex in neurons. Collectively, our data define an unexpected yet commanding molecular platform that determines vertebrate membrane excitability.

\section{Results}

Identification of novel CaMKII-binding proteins. We screened the human genome for novel CaMKII-binding proteins using an algorithm derived from the CaMKII autoregulatory domain sequence and identified 32 candidates. Putative CaMKII-binding molecules included nuclear, cytosolic, and mitochondrial proteins with a host of disparate roles, including cell metabolism, cytoskeletal dynamics, and signaling (Figure 1, A and B). All CaMKII gene products $(\alpha, \beta, \gamma$, and $\delta)$ were recognized by the screen; notably, only 1 known CaMKII-binding partner was identified (35). All candidates were cloned from human tissue (brain or heart), and CaMKII-binding activity was assessed by in vitro binding assays using radiolabeled target proteins and activated CaMKII (CaMKII T287D). Of 32 candidates containing the consensus CaMKII autoregulatory domain consensus motif, only 12 clones displayed remarkable CaMKII-binding activity in vitro (see Supplemental Figure 1 for examples; supplemental material available online with this article; doi:10.1172/JCI43621DS1). Positive targets included critical signaling molecules (PKCE, phospholipase A2 zeta; ref. 36), cytoskeletal-associated proteins (SPTBN4 and NEDD1, ref. 37; girdin, ref. 38), and ion channel regulatory molecules. Notably, targets that shared the highest 
A

\begin{tabular}{|c|c|}
\hline & \\
\hline $2 \mathrm{G \quad} \quad(27$ & BSTYA SMMHROETYPCL. \\
\hline CNB1 $\quad(486-5$ & \\
\hline ACNB2 $\quad(486-t$ & RETFDSE \\
\hline$\overline{E L C A 3 P} \quad(84-10$ & ETYD \\
\hline $1352-$ & \\
\hline FAM 40B (341- & RGSRRQLLT \\
\hline SPTBN4 $\quad(2292-$ & \\
\hline ANKRD26 (11 & VEER \\
\hline $\mathrm{CDC} 144 \mathrm{~A}$ & BQSKLH \\
\hline CCDC144C & \\
\hline $\mathrm{CDC} 138$ & EEE \\
\hline $\mathrm{CDC}_{14} \quad 69$ & SGS \\
\hline CEP72 & \\
\hline GCR8 $\quad(697$ & \\
\hline FPT2 $\quad(62$ & \\
\hline RDN $\quad(142$ & \\
\hline RKCE (215 & PDQV \\
\hline MDM2-D (19- & ESEDYS \\
\hline HOT2 $\quad 432$ & CREOP \\
\hline EDD1 1432 & KDSF \\
\hline $\mathrm{BSCN} \quad(33$ & 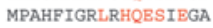 \\
\hline PLA2G4F $(138-155$ & SQELQ \\
\hline SAPS1 $(233-250)$ & PDQLLATLEKQETIEQL \\
\hline SPTA1 195 & 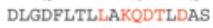 \\
\hline SPTA2 $(2007$ & TFDAG \\
\hline $\mathrm{TSC} 22 \mathrm{D} 3-2$ & NTDKLNSIMRQDSLEPV \\
\hline & OYRP \\
\hline $19700-1$ & MDSRCTVLRKQDSGEAP \\
\hline & \\
\hline ZNF347(110-127) & GEVFQTVMLEF \\
\hline
\end{tabular}

B

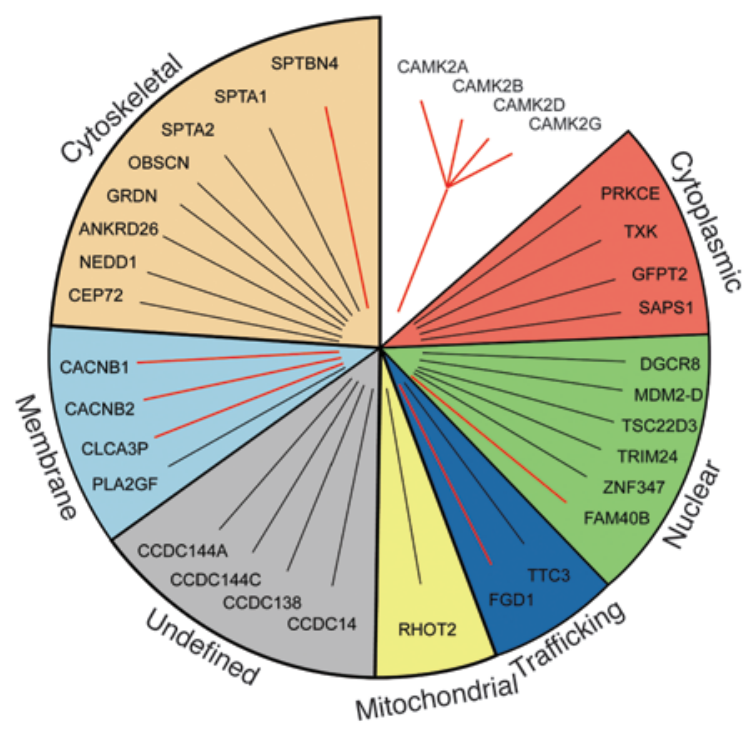

At the cellular level, $\beta_{\mathrm{IV}}$-spectrin was concentrated at the intercalated disc of cardiomyocytes (colocalized with $\mathrm{N}$-cadherin; Figure 2, $\mathrm{H}, \mathrm{I}, \mathrm{K}$, and L, and Supplemental Figure 2), an excitable membrane domain critical for cardiac action potential (AP) initiation and impulse conduction. We identified 2 distinct subcellular distributions of CaMKII in myocytes. Consistent with a potential in vivo interaction, CaMKIId (the primary CaMKII isoform in heart; ref. 41) was coexpressed with $\beta_{\mathrm{IV}}$-spectrin at the intercalated disc (Figure 2, J and M). A second population of CaMKII $\delta$ was localized to the myocyte transversetubule network, apparently independent of $\beta_{\mathrm{IV}}$-spectrin (Figure 2J, yellow arrowheads). Together, our data identify $\beta_{\mathrm{IV}}$-spectrin as a cardiac protein that associates with endogenous CaMKII.

$\beta_{I V}$-spectrin organizes a macromolecular signaling complex in the heart. In the central nervous system, $\beta_{\mathrm{IV}^{-}}$ spectrin and ankyrin-G are highly enriched at axon initial segments (AISs) and nodes of Ranvier, and the clustering of $\mathrm{Na}^{+}$channels at

sequence identity with the CaMKII autoregulatory domain (i.e., $S P T B N 4)$ retained the most consistent kinase binding activity (Figure 1A and Supplemental Figure 1).

$\beta_{I V}$-spectrin associates with CaMKII. SPTBN4 encodes $\beta_{\mathrm{IV}}$-spectrin (Figure 2A), an actin-associated protein with roles in nervous system membrane biogenesis and maintenance as well as in ion channel clustering $(39,40)$. Importantly, all $\beta_{\mathrm{IV}}$-spectrin orthologs harbored sequences nearly identical to the CaMKII autoregulatory motif (Figure 2B). Based on these characteristics, we hypothesized that $\beta_{\mathrm{IV}}$-spectrin may target CaMKII in excitable cells. We first verified the $\beta_{\mathrm{IV}}$-spectrin/CaMKII association using radiolabeled CaMKII $\delta$ and a biotinylated peptide mimicking the putative kinase-binding domain in human $\beta_{\mathrm{IV}}$-spectrin (CTP-P; residues 2,292-2,317). Consistent with a specific interaction, CTP-P, but not scrambled peptide control (CTP-C), bound radiolabeled CaMKII (Figure 2C).

$\beta_{I V}$-spectrin is expressed in the heart and associates with CaMKII in vivo. Based on the critical role of CaMKII in regulating cardiac membrane excitability (5), we tested human heart for $\beta_{\mathrm{IV}}$-spectrin expression. Notably, both brain and heart expressed $\beta_{\mathrm{IV}}$-spectrin mRNA (Figure 2D). Moreover, $\beta_{\mathrm{IV}}$-spectrin $\Sigma 1$ and $\Sigma 6$ isoforms were readily detected in the left ventricle of multiple species by immunoblot, albeit at lower levels than were observed in brain (Figure 2E). In agreement with peptide binding experiments using radiolabeled CaMKII, CTP-P, but not CTP-C, interacted with endogenous CaMKIIS from heart (Figure 2F). Moreover, consistent with an in vivo interaction, endogenous $\beta_{\mathrm{IV}}$-spectrin associated with endogenous CaMKII $\delta$ in coimmunoprecipitation experiments (Figure $2 \mathrm{G}$ ). these sites depends on their interaction with ankyrin-G $(31,42)$. Furthermore, mice deficient in $\beta_{\mathrm{IV}}$-spectrin display defects in neuronal $\mathrm{Na}^{+}$channel clustering and function (29). In heart, ankyrin- $\mathrm{G}$ targets voltage-gated $\mathrm{Na}^{+}$channels $\left(\mathrm{Na}_{v} 1.5\right)$ to the intercalated disc $(43,44)$, and cardiac $\mathrm{Na}^{+}$channel membrane regulation has been associated with CaMKII activity (16). We therefore tested whether the $\beta_{\mathrm{IV}}$-spectrin/CaMKII complex formed a macromolecular complex with ankyrin-G and $\mathrm{Na}_{v} 1.5$ in heart. Similar to $\beta_{\mathrm{IV}}$-spectrin and CaMKII $\delta$, ankyrin-G and $\mathrm{Na}_{\mathrm{v}} 1.5$ were enriched at the myocyte intercalated disc (Figure 2, N-Q). Moreover, ankyrin$\mathrm{G}$ and $\mathrm{Na}_{\mathrm{v}} 1.5$ associated with both $\beta_{\mathrm{IV}}$-spectrin and CaMKII by coimmunoprecipitation (Figure $2, \mathrm{R}-\mathrm{U}$ ). Thus, $\beta_{\mathrm{IV}}$-spectrin coordinates an in vivo cardiac macromolecular complex, effectively linking a critical signaling protein (CaMKIII) with its target substrate $\left(\mathrm{Na}_{v} 1.5\right)$ at a specialized cellular domain.

$\beta_{I V}$-spectrin targets CaMKII to cardiomyocyte intercalated disc. We evaluated the role of $\beta_{\mathrm{IV}}$-spectrin for CaMKII targeting in vivo using primary cardiomyocytes and heart tissue from the $q v^{3 J}$ mouse strain (45). $q v^{3 J}$ mice harbor a nucleotide insertion (InsT6786) in the $\beta_{\mathrm{IV}}$-spectrin gene immediately proximal to the CaMKII-binding motif, resulting in a premature C-terminal truncation (Figure $3 \mathrm{~A}$ and ref. 45 ). In contrast to $\mathrm{WT} \beta_{\mathrm{IV}}$-spectrin, the mutant $q v^{3 J}$ polypeptide lacked cardiac CaMKIII-binding activity (Figure 3, B-D), as predicted by our peptide binding studies (Figure 2, C and F). However, both WT and mutant proteins retained binding activity for ankyrin-G (Figure $3 \mathrm{E}$ ), actin, and $\alpha$-spectrin (data not shown). Consistent with the location of the $q v^{3 J}$ mutation, we observed association of ankyrin-G with CaMKII 
A
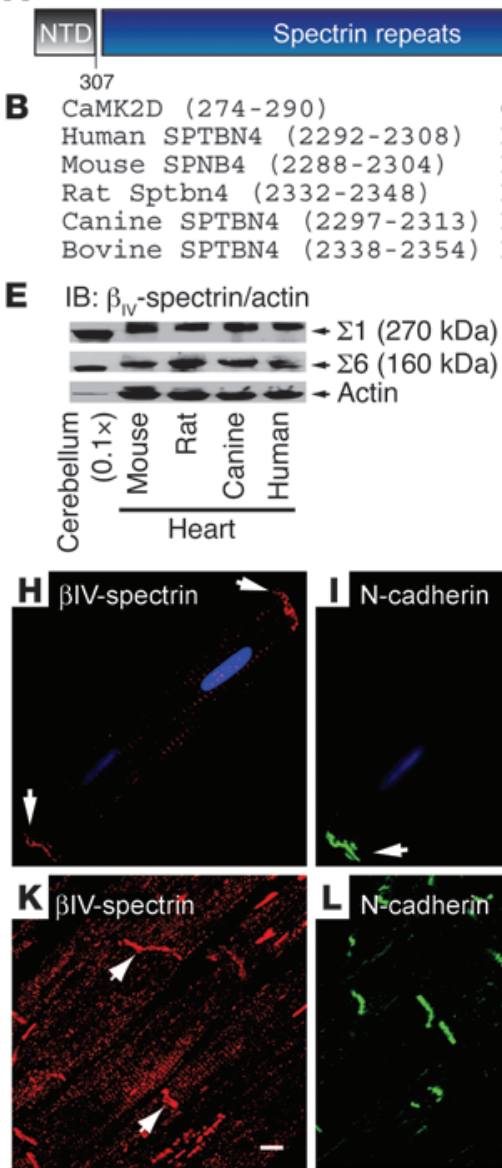

R

IP: AnkG IB: CaMKII $55 \mathrm{kDa}$
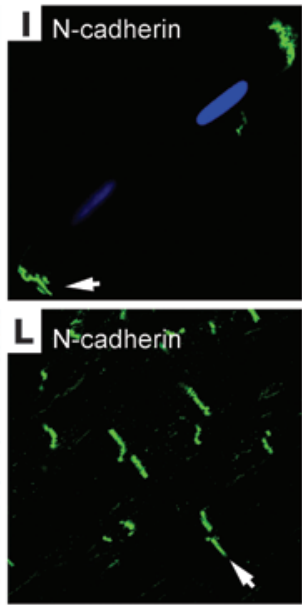

S IP: AnkG IB: $\beta_{\text {IV }}$ spectrin $268 \mathrm{kDa}$

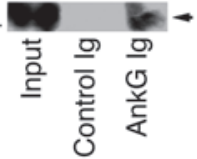

\section{C}

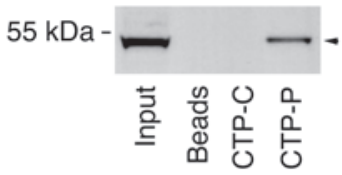

D

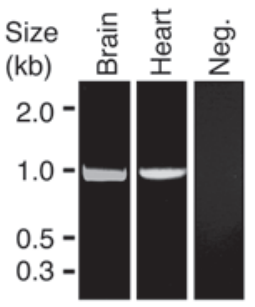

G IB: CaMKIIס

$55 \mathrm{kDa} \cdot$

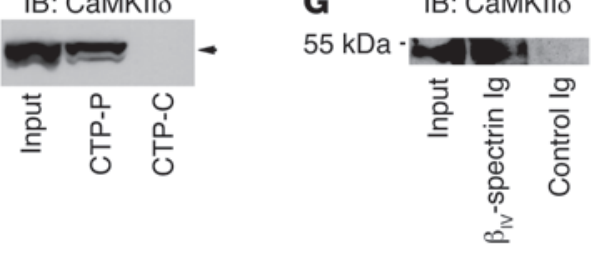

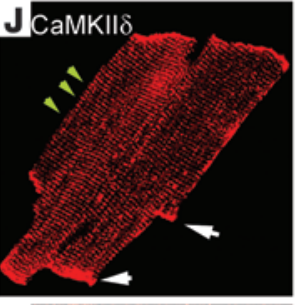
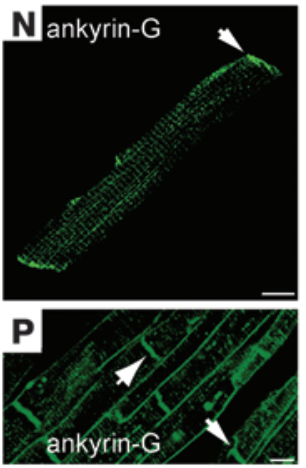

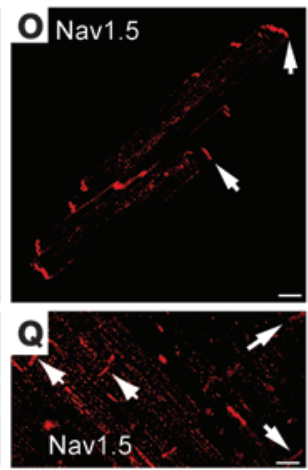

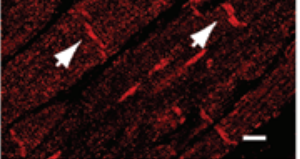

T

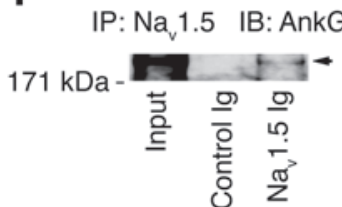

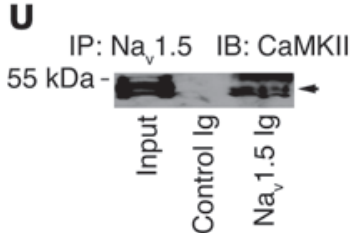

\section{Figure 2}

$\beta_{\mathrm{IV}}$-spectrin is a CaMKII-binding protein in heart. (A) $\beta_{\mathrm{IV}}$-spectrin contains an N-terminal actin-binding domain (NTD), 17 spectrin repeats, and specific and C-terminal domains (SD/CTD). The putative CaMKII-binding site is denoted by an asterisk. (B) The putative CaMKII-binding domain in $\beta_{\mathrm{IV}}$-spectrin was homologous to a CaMKII $\delta$ autoregulatory domain motif and conserved across orthologs. (C) CTP-P bound radiolabeled

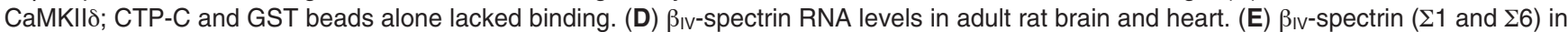
ventricular lysates from multiple species. $\beta_{\mathrm{IV}}$-spectrin was expressed approximately 8-10 fold higher in cerebellum than in heart. Cardiac $\beta_{\mathrm{IV}}$ spectrin migrated approximately $4 \mathrm{kDa}$ larger than did cerebellar $\beta_{\mathrm{IV}}$-spectrin. (F) CTP-P, but not CTP-C, associated with CaMKII $\delta$ from rat heart. (G) Endogenous CaMKII $\delta$ and $\beta_{\mathrm{IV}}$-spectrin coimmunoprecipitated from adult heart lysate. (H and I) $\beta_{\mathrm{IV}}$-spectrin and $\mathrm{N}$-cadherin in rat cardiomyocytes. Nuclei are shown by Topro-3 dye (blue). (J) CaMKII $\delta$ localization in adult rat myocytes. CaMKII $\delta$ localized to the intercalated disc (white arrows) here and to a second population at transverse-tubules (yellow arrows). Ventricular sections stained for (K) $\beta_{\mathrm{IV}}$-spectrin, (L) N-cadherin, and (M) CaMKIII showed coexpression of these proteins at the intercalated disc (white arrows). ( $\mathbf{N}$ and $\mathbf{P})$ Ankyrin- $\mathbf{G}$ and $(\mathbf{O}$ and $\mathbf{Q}) \mathbf{N a}{ }_{v} 1.5$ were also found at the intercalated disc (white arrows) in rat myocytes and tissue sections. (R-U) Coimmunoprecipitation studies demonstrate cardiac complex of $\beta_{\mathrm{IV}}$-spectrin, CaMKIII, ankyrin-G (AnkG), and Na 1.5 . Scale bars: $10 \mu \mathrm{m}(\mathbf{H}-\mathbf{Q})$.

from WT but not $q v^{3 J}$ heart (Figure $3 \mathrm{~F}$ ). Thus, the $\beta_{\mathrm{IV}}$-spectrin $q v^{3 J}$ mouse represented an ideal in vivo system to directly test the role of $\beta_{\mathrm{IV}}$-spectrin for CaMKII targeting.

Consistent with the location of the $q v^{3 J}$ mutation, $q v^{3 J}$ mouse cardiomyocytes displayed normal expression of $\beta_{\mathrm{I} V}$-spectrin, ankyrin-G, and $\mathrm{Na}_{\mathrm{v}} 1.5$ as well as normal levels of intercalated disc proteins $\mathrm{N}$-cadherin and $\beta$-catenin (Figure 3, G, H, K, and L, and Supplemental Figures 3 and 4). However, CaMKIId expression levels were modestly reduced in $q v^{3}$ hearts (Figure $3 \mathrm{G}$ and Supplemental Figure 3). Parallel immunostaining experiments revealed a striking absence of CaMKIID from the myocyte intercalated disc (Figure 3, I and N, and Supplemental Figure 5). In contrast, CaMKIIS localization at transverse-tubule membranes was unaffected (Figure 3 , I and $\mathrm{N}$, and Supplemental Figure 5), indicative of a $\beta_{\mathrm{IV}}$-spectrin-independent pathway that localizes CaMKII to transversetubules. Notably, we also observed dramatic reduction of acti- 
A

Actin-binding Ankyrin-binding binding binding

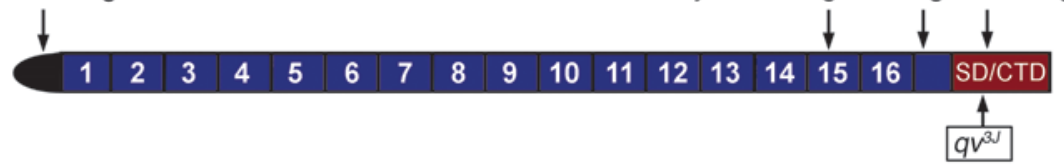

B $\alpha$-spectrin-CaMKII-

Ankyrin-binding binding binding

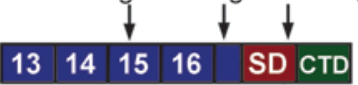

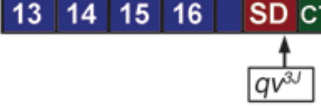

C

\begin{tabular}{llllll|l|l}
13 & 14 & 15 & 16 & $S D$ & $\beta_{\mathrm{IV}}-W T$ \\
\hline
\end{tabular}

$\begin{array}{lllllll}13 & 14 & 15 & 16 & S\left[\beta_{I V}-q v^{3}\right.\end{array}$
D

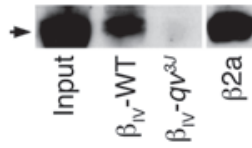

E

IB: ankyrin-G

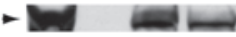

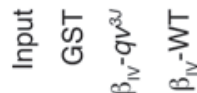

$\mathbf{F}$

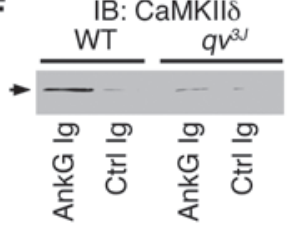

G

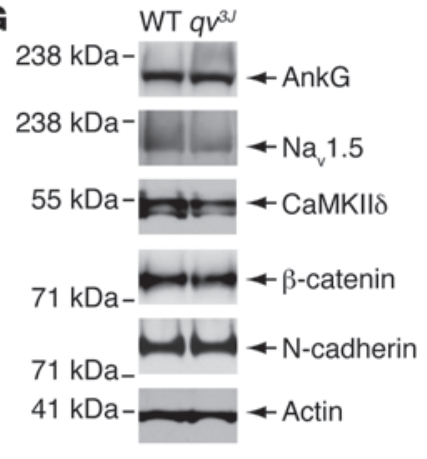

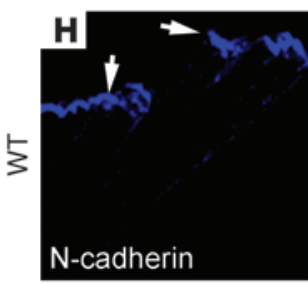

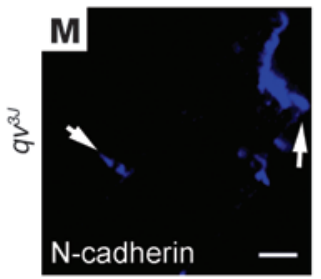

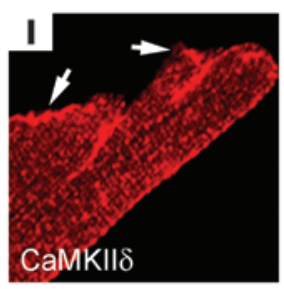

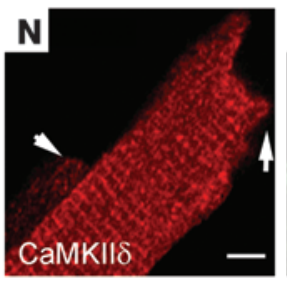

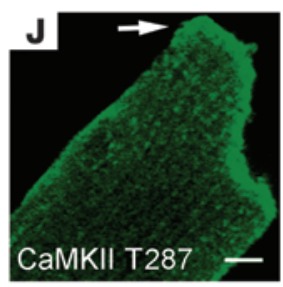
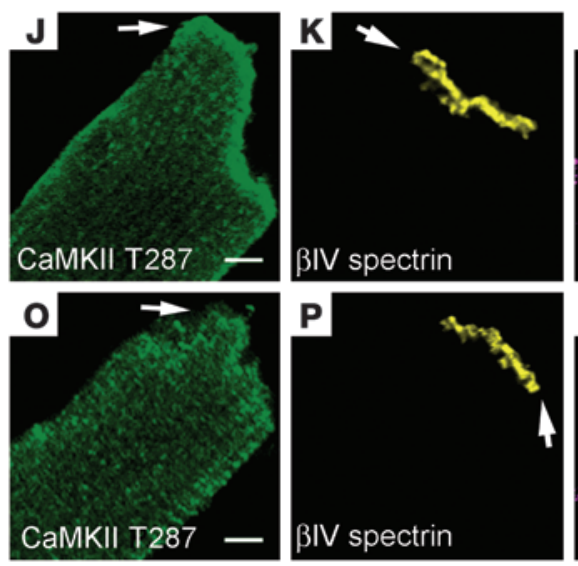
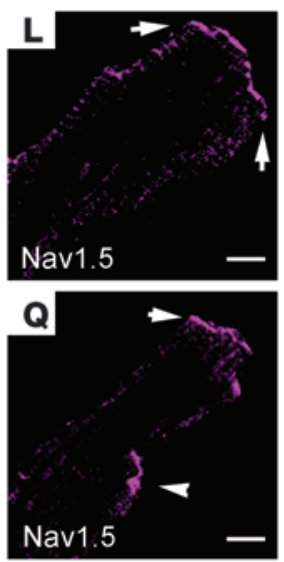

Figure 3

$\beta_{\mathrm{IV}}$-spectrin is required for CaMKII $\delta$ targeting. (A) $\beta_{\mathrm{IV}}$-spectrin organization in WT and $q v^{3 \mathrm{~J}}$ animals. $q v^{3 \mathrm{~J}}$ animals lacked a CaMKII-binding domain, but retained actin-, ankyrin-, and $\alpha$-spectrin-binding domains. (B and C) Schematic of control GST- $\beta_{\mathrm{IV}}$-spectrin fusion protein encompassing spectrin repeats 13-17 and the CaMKII-binding domain ( $\beta$ IV-WT) and truncated mutant lacking CaMKII-binding domain ( $\left.\beta I V-q v^{3 J}\right)$. (D) $\beta$ IV-Spectrin WT and $q v^{3 J}$ GST fusion proteins were incubated with detergent-soluble rat heart lysate and analyzed by immunoblot (CaMKII $\delta$ ). L-type Ca ${ }^{2+}$ channel $\beta 2 a$ subunit was also expressed as a GST fusion protein and used as positive control. CaMKII $\delta$ bound to the $\beta 2 a$ and WT GST fusion proteins, but not to the $q v^{3 J}$ GST fusion protein. Lanes were run on the same gel but were noncontiguous (white line). (E) $\beta_{\mathrm{IV}}$-spectrin WT and $q v^{3 J} \mathrm{GST}$ fusion proteins retained binding activity for ankyrin-G. (F) Coimmunoprecipitation studies showing association of ankyrin-G and CaMKII $\delta$ in WT, but not $q v^{3 J}$, hearts. (G) Expression of ankyrin-G, $\mathrm{Na}_{v} 1.5$, CaMKII $\delta, \beta$-catenin, and $\mathrm{N}$-cadherin in heart lysates from WT and $q v^{3 J}$ animals. Actin is shown as loading control. ( $\mathbf{H}-\mathbf{Q})$ Permeabilized adult rat cardiomyocytes from $(\mathbf{H}-\mathbf{L}) \mathbf{W T}$ and $(\mathbf{M}-\mathbf{Q}) q^{3 J}$ hearts were immunostained for $(\mathbf{H}$ and

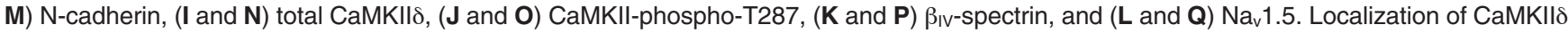
(total and phospho-T287) to the intercalated disc (white arrows) was disrupted in $q v^{3 \jmath}$ cardiomyocytes. Scale bars: $10 \mu \mathrm{m}(\mathbf{H}-\mathbf{Q})$.

vated CaMKIIS (identified by CaMKII T287 phosphorylation) at the intercalated disc of $q v^{3 J}$ ventricular cardiomyocytes (Figure 3, $\mathrm{J}$ and $\mathrm{O}$ ). Finally, consistent with the noted lack of effect of the $q v^{3 J}$ allele on ankyrin-G binding, we observed no difference in $\mathrm{Na}_{v} 1.5$ (Figure 3, L and Q) or ankyrin-G (data not shown) intercalated disc targeting. We believe our findings identify $\beta_{\mathrm{IV}}$-spectrin as a novel CaMKII targeting protein in excitable cardiac cells.

$\beta_{I V}$-spectrin is required for local CaMKII signaling in cardiomyocytes. We tested the requirement of the $\beta_{\mathrm{IV}}$-spectrin-dependent CaMKII targeting pathway for normal cardiomyocyte function by assess- ing the activity of the resident intercalated disc voltage-gated $\mathrm{Na}^{+}$ channel in primary $q v^{3 J}$ ventricular cardiomyocytes. $q v^{3 J}$ cardiomyocytes displayed aberrant CaMKII-dependent $\mathrm{Na}^{+}$channel regulation at baseline and in response to the $\beta$-adrenergic receptor agonist isoproterenol, which activates CaMKII (5). Specifically, $q v^{3 J}$ myocytes showed a significant increase in peak $\mathrm{Na}^{+}$current $\left(I_{N a}\right.$; Figure 4, A-C) and a depolarizing shift in steady-state inactivation (Figure 4, D and E) compared with WT mouse ventricular cardiomyocytes. Additionally, persistent $I_{N a}\left(I_{N a, p}\right)$, measured as current amplitude $50 \mathrm{~ms}$ after the peak value, was significantly 
A

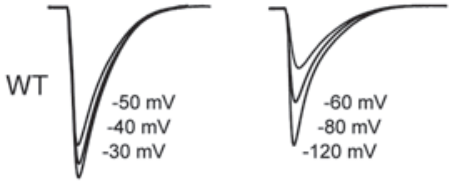

B
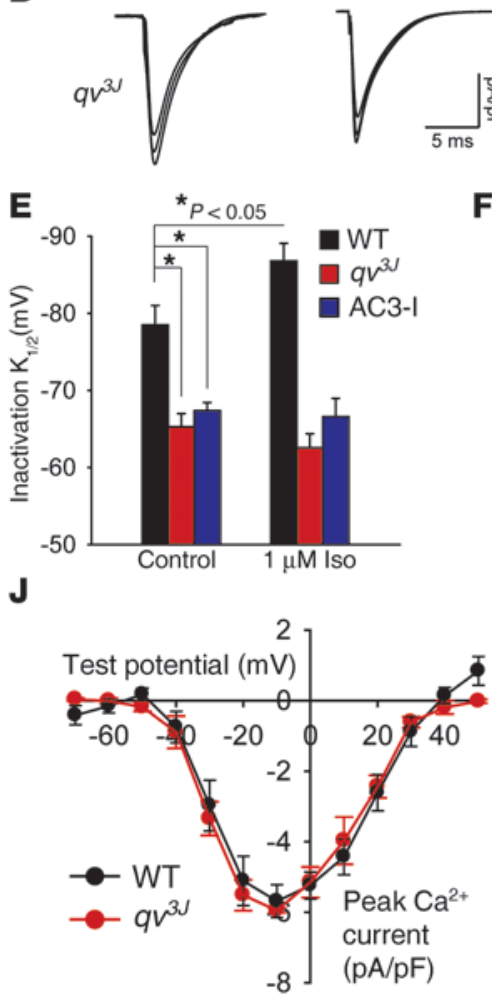

C

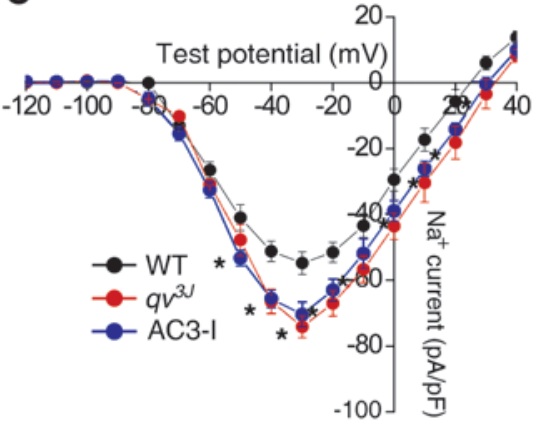

G

$\mathbf{F}$

$$
\frac{}{5 \mathrm{~ms}}
$$

H

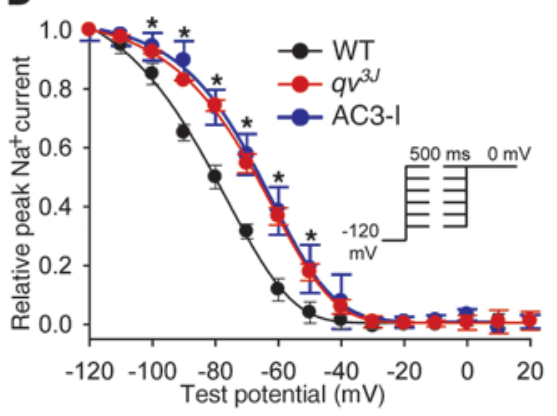

I

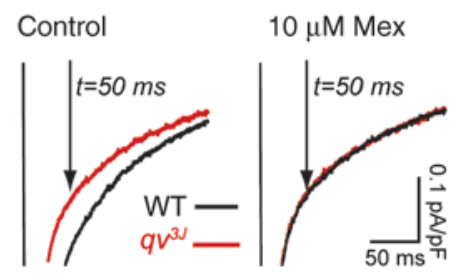

K

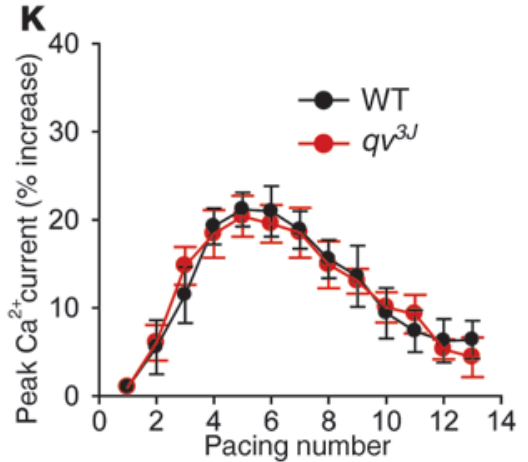

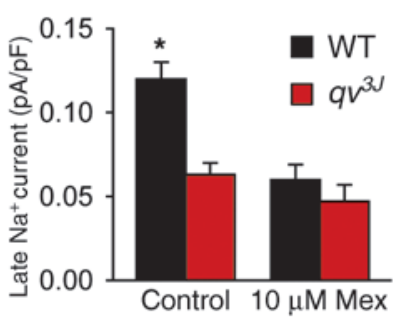

L

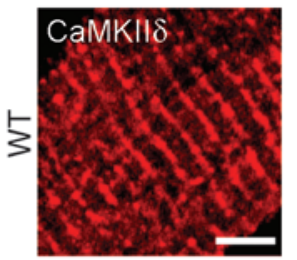

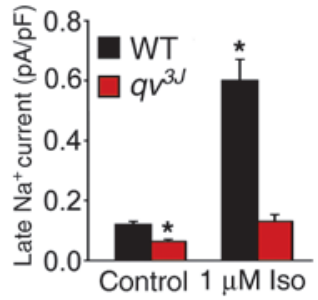

M

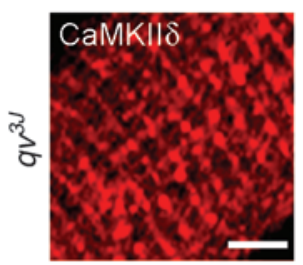

Figure 4

$\beta_{\mathrm{IV}}$-Spectrin/CaMKII complex is required for myocyte $\mathrm{Na}^{+}$channel function. (A and $\left.\mathbf{B}\right)$ Whole-cell patch clamp $I_{\mathrm{Na}}$ traces from WT and $\mathrm{qv}^{3 \mathrm{~J}}$ cardiomyocytes. Test pulse potential is listed next to each trace. (C) Current-voltage relationship for cardiomyocytes from WT, $q v^{3 J}$, and AC3-I mice ( $n=8$ per group). ${ }^{*} P<0.05$ versus WT. (D and E) Voltage-gated $\mathrm{Na}^{+}$channel steady-state inactivation measured from WT, $q v^{33}$, and AC3-I cardiomyocytes $\left(n=8\right.$ per group). ${ }^{*} P<0.05$ versus WT. Pulse protocol is shown in the inset of $\mathbf{D}$. ( $\mathbf{F}$ and $\left.\mathbf{G}\right) I_{N a, p}$ from WT and $q v^{3 J}$ mice with or without $10 \mu \mathrm{M}$ mexiletine. Persistent current was determined as amplitude $50 \mathrm{~ms}$ after time of peak. ( $H$ and I) $I_{N a, p}$ in WT $(n=10)$ and $q v^{3 J}(n=17)$ cardiomyocytes at baseline and in the presence of $10 \mu \mathrm{m}$ mexiletine or isoproterenol. ${ }^{*} P<0.05$. (J) Whole-cell patch clamp $\mathrm{Ca}^{2+}$ current-voltage relationship for WT $(n=9)$ and $q v^{3 J}(n=8)$ cardiomyocytes. $(K) \mathrm{Ca}^{2+}$ current facilitation (peak current in response to a train of depolarizing voltage pulses to $0 \mathrm{mV})$ in $\mathrm{WT}(n=9)$ and $q v^{3 \mathrm{~J}}(n=7)$ cardiomyocytes. Peak current is expressed as percent increase from first pulse. ( $\mathbf{L}$ and $\mathbf{M})$ Transverse-tubule CaMKII labeling was preserved in $q v^{3\lrcorner}$ mouse myocytes. Scale bars: 5 um ( $(\mathbf{L}$ and $\mathbf{M})$.

reduced in $q v^{3 J}$ myocytes compared with littermate controls (Figure 4, F-I). Differences in $I_{N a, p}$ between genotypes were eliminated by mexiletine (Figure 4, F-H), a cardiac $\mathrm{Na}_{v} 1.5$ antagonist used to treat patients with type 3 long QT syndrome, a genetic syndrome that predisposes affected hearts to increased $I_{N a, p}$ and arrhythmias. Isoproterenol $(1 \mu \mathrm{M})$ produced a depolarizing shift in steady-state inactivation and increased $I_{N a, p}$ in ventricular cardiomyocytes derived from WT mice, but not $q v^{3 J}$ mice or AC3-I transgenic mice (Figure 4, E and I), which overexpress a CaMKIIinhibitory peptide (5). In fact, we verified that differences in intercalated disc $\mathrm{Na}^{+}$channel properties were due to specific elimination of CaMKII by testing the identical parameters in ventricular cardiomyocytes derived from AC3-I mice. Notably, all tested $I_{N a}$ parameters were identical between AC3-I and $q v^{3} J$ mice (Figure 4,
$\mathrm{C}-\mathrm{E})$. These findings demonstrate that the CaMKII-binding function of $\beta_{\mathrm{IV}}$-spectrin is required for CaMKII actions on $I_{\mathrm{Na}}$ in excitable cardiac myocytes.

Finally, past work has demonstrated a clear role of CaMKII in regulation of L-type $\mathrm{Ca}^{2+}$ channel $\left(\mathrm{Ca}_{v} 1.2\right) \mathrm{Ca}^{2+}$ current $\left(I_{C a, L}\right)$ facilitation (35). As this functional property is specific to the cardiomyocyte transverse-tubule membrane network (35), we tested whether loss of CaMKII targeting by $\beta_{\mathrm{IV}}$-spectrin in $q v^{3 J}$ mice would display defects in $\mathrm{Ca}^{2+}$ current facilitation. Consistent with a highly selective role of $\beta_{\mathrm{IV}}$-spectrin in the organization of CaMKII at the intercalated disc, we observed no differences in peak $\mathrm{Ca}^{2+}$ current or $\mathrm{Ca}^{2+}$ current facilitation between $q v^{3 J}$ and WT cardiomyocytes (Figure 4, J-M). Moreover, WT and $q v^{3 J}$ cardiomyocytes showed no difference in either total myocyte $\mathrm{K}^{+}$current or the transient 
A
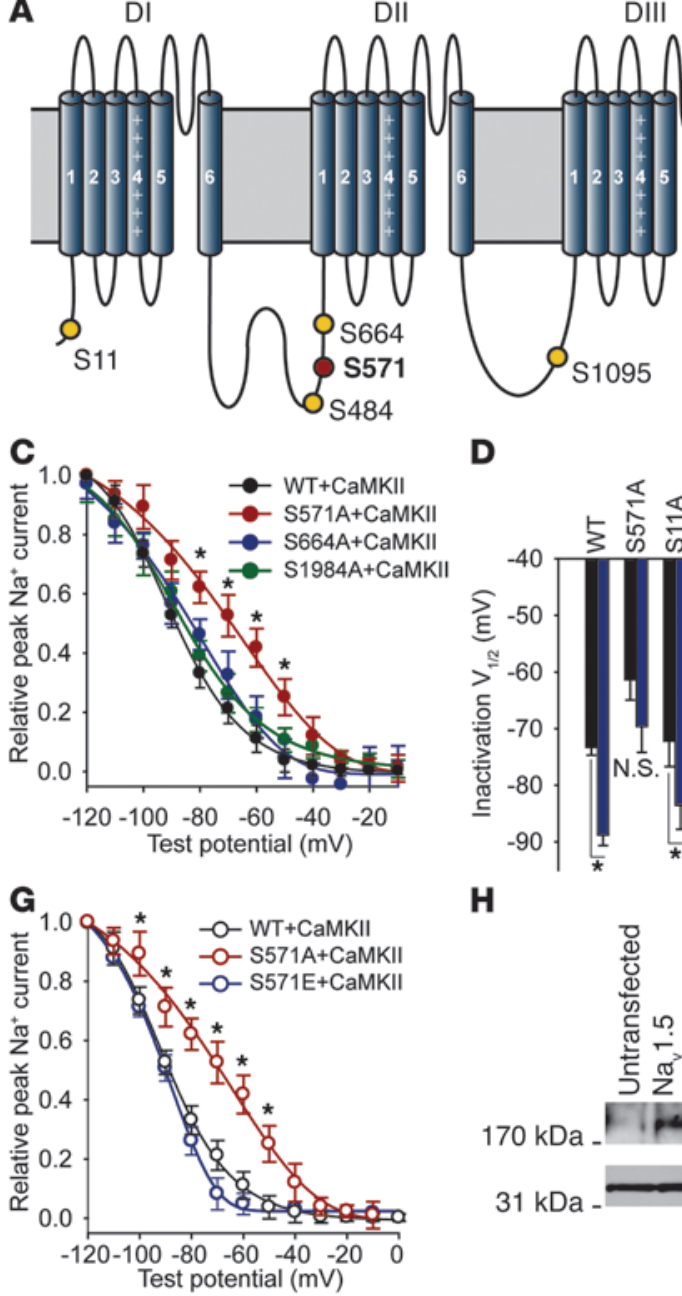

D

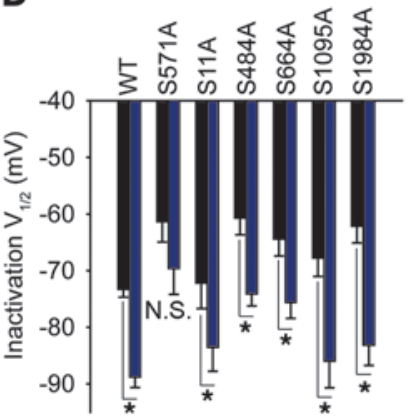

H

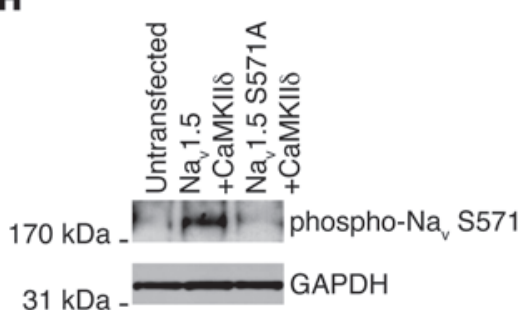

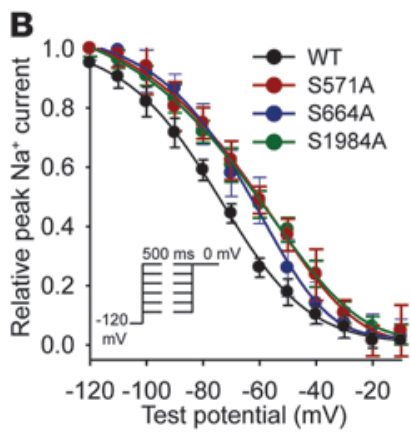

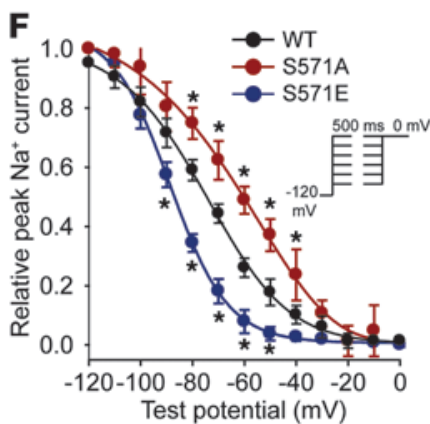

I

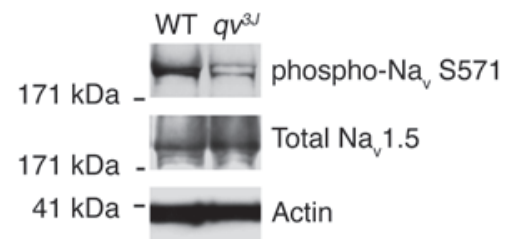

\section{Figure 5}

$\beta_{\mathrm{IV}}$-spectrin/CaMKII regulates $\mathrm{Na}_{\mathrm{v}} 1.5$ phosphorylation. (A) CaMKII consensus phosphorylation sites in intracellular domains of $\mathrm{Na}_{\mathrm{v}} 1.5$. (B and C) $\mathrm{Na}^{+}$channel steady-state inactivation measured from WT and $\mathrm{Na}_{v} 1.5$ mutant channels expressed in HEK cells. ${ }^{*} P<0.05$ versus WT. (D) Summary data showing depolarizing shift in steady-state inactivation $\mathrm{V}_{1 / 2}$ following CaMKII activation for WT and all mutants except S571A. Black, before CaMKII activation; blue, after CaMKII activation. (E) CaMKII phosphorylation assay on intracellular domains of $\mathrm{Na}_{\mathrm{v}} 1.5$. $\beta 2 a$ was used as positive control. Asterisks denote location of purified proteins. (F and $\mathbf{G}) \mathrm{Na}^{+}$channel steady-state inactivation measured from WT, S571A, and S571E (phosphomimetic) channels expressed in HEK cells. ${ }^{*} P<0.05$ versus WT. (H) Na 1.5 S571 antibody recognized WT, but not $\mathrm{Na}_{v} 1.5$ S571A mutant, channels. WT and mutant channels were expressed at equivalent levels in HEK293 cells overexpressing active CaMKIII. (I) Immunoblots showing reduced levels of phospho-Nav1.5 S571, but unchanged total $\mathrm{Na}_{v} 1.5$ levels, in $q v^{3\lrcorner}$ versus WT heart lysates. Actin is shown as loading control.

outward $\mathrm{K}^{+}$current $\left(I_{t o}\right.$; Supplemental Figure $6 ; n=12$ myocytes/ genotype; $P=\mathrm{NS})$, the primary murine repolarizing current (46) and a target for CaMKII in heart $(47,48)$. Collectively, these data provide the first description to our knowledge of the molecular mechanism underlying CaMKII targeting to the cardiomyocyte intercalated disc, and establish $\beta_{\mathrm{IV}}$-spectrin as a bona fide CaMKII targeting protein in vivo. Notably, although our data link the $\beta_{\mathrm{IV}}$-spectrin/CaMKII complex with $\mathrm{Na}_{\mathrm{v}} 1.5$ regulation (and not $I_{\mathrm{Ca}, L}$ or $I_{t o}$ regulation), they do not exclude other intercalated disc proteins (e.g., channels, receptors, and signaling molecules) as potential targets of the regulatory complex.

CaMKII regulates $\mathrm{Na}_{v} 1.5$ via direct phosphorylation of $\mathrm{Na}_{v} 1.5 \mathrm{~S} 571$. While CaMKII has previously been shown to regulate cardiac $I_{\mathrm{Na}}$ $(16,18)$, the molecular mechanism underlying this modulation has remained elusive. Based on our findings, we hypothesized that CaMKII directly regulates $I_{N a}$ by direct phosphorylation of $\mathrm{Na}_{v} 1.5$. To test this hypothesis in cells, we measured $I_{N a}$ properties from a library of full-length human $\mathrm{Na}_{v} 1.5$ (SCN5A) mutants engineered to harbor single serine-to-alanine mutations at all putative consensus CaMKII phosphorylation sites (RXX[S/T]; Figure 5A). Notably, with the exception of S571A (localized in the cytoplasmic domain loop DI-DII), WT $\mathrm{Na}_{v} 1.5$ and all mutant $\mathrm{Na}_{\mathrm{v}} 1.5$ channels showed a significant depolarizing shift in $\mathrm{Na}^{+}$channel steady-state inactivation in the presence of CaMKII T287D (Figure 5, B-D). Based on these findings, we tested an additional S571E (phosphomimetic) mutant and observed a significant leftward shift in steady-state inactivation at baseline, with no CaMKII response in $I_{\mathrm{Na}}$ (Figure 5, $\mathrm{F}$ and $\mathrm{G})$. These biophysical data strongly suggest that $\mathrm{Na}_{v} 1.5$ is 

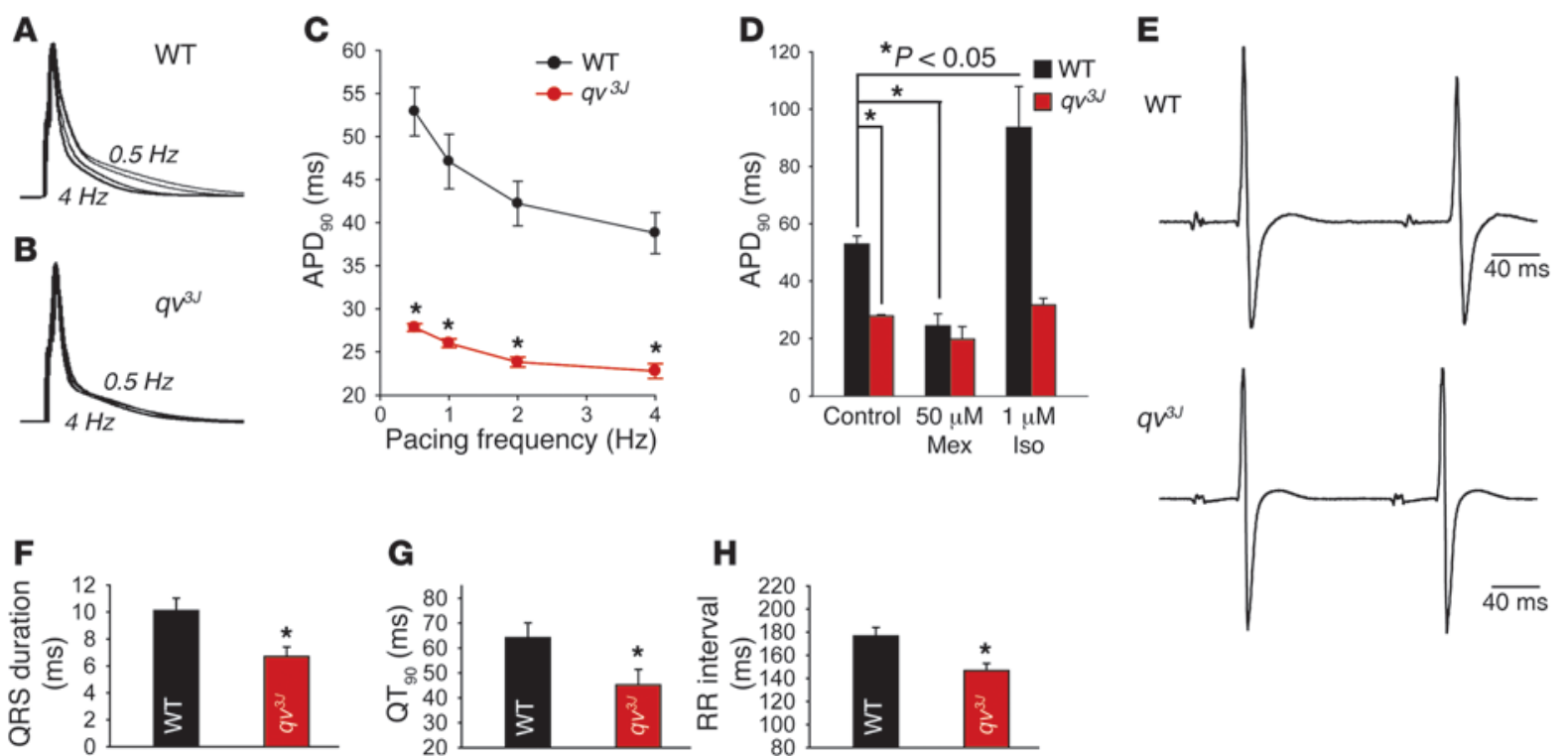

Figure 6

$\beta_{\text {IV }}$ spectrin/CaMKII signaling complex is critical for normal cardiac cell membrane excitability. (A and B) Representative APs and (C) APD 90 in WT $(n=14)$ and $q v^{3 J}(n=16)$ cardiomyocytes paced at $4,2,1$, or $0.5 \mathrm{~Hz}$. ${ }^{*} P<0.05$. (D) Differences in APD 90 were eliminated by application of $50 \mu \mathrm{M}$ mexiletine, but exaggerated by $1 \mu \mathrm{M}$ isoproterenol (pacing frequency, $0.5 \mathrm{~Hz}) . n=14(\mathrm{WT}) ; 16\left(q v^{3 J}\right)$. ${ }^{*} P<0.05$. (E) Representative electrocardiograms recorded from Langendorff-perfused WT and $q v^{3 \mathrm{~J}}$ hearts and summary data for (F) QRS duration (G), QT interval at $90 \%$ repolarization $\left(\mathrm{QT}_{90}\right)$, and $(\mathrm{H}) \mathrm{RR}$ interval for $q v^{3\lrcorner}$ versus WT. $n=10(\mathrm{WT}) ; 10\left(q v^{3\lrcorner}\right)$. ${ }^{*} P<0.05$.

directly phosphorylated by CaMKII, and that the CaMKII regulation is dependent on $\mathrm{Na}_{v} 1.5 \mathrm{~S} 571$. In vitro phosphorylation assays (using purified $\mathrm{Na}_{v} 1.5$ cytoplasmic domains and activated CaMKII) validated our functional findings, showing that $\mathrm{Na}_{\mathrm{v}} 1.5$ was directly phosphorylated on DI-DII (Figure 5E) and that S571 was a primary site for this regulation (Supplemental Figure 7). Together, these data identify S571 in the DI-DII loop as a critical site for regulation of $\mathrm{Na}_{v} 1.5$ activity by CaMKII.

$\beta_{I V}$ spectrin regulates direct phosphorylation of $\mathrm{Na}_{v} 1.5$ by $\mathrm{CaMKII}$. We created a custom phosphospecific antibody against $\mathrm{Na}_{v} 1.5 \mathrm{~S} 571$ to test the role of the $\beta_{\mathrm{IV}}$-spectrin/CaMKII pathway for $\mathrm{Na}_{\mathrm{v}} 1.5$ regulation in heart (Figure 5, H and I). Consistent with (a) a role of $\beta_{\mathrm{IV}}$-spectrin for CaMKII regulation in vivo and (b) a role of CaMKII for direct regulation of $\mathrm{Na}_{v} 1.5$ in vivo, we observed decreased levels of phospho- $\mathrm{Na}_{v} 1.5$ S571 in $q v^{3 J}$ compared with WT hearts (Figure 5I and Supplemental Figure 8). In contrast, total $\mathrm{Na}_{\mathrm{v}} 1.5$ levels were unchanged between WT and $q v^{3 J}$ mice (Figure 5I). These data support the hypothesis that $\beta_{\mathrm{IV}}$-spectrin creates a platform for regulation of cardiac $\mathrm{Na}^{+}$channel activity through direct phosphorylation by CaMKII.

$\beta_{I V}$-spectrin is critical for cardiac membrane excitability. We next tested the role of $\beta_{\mathrm{IV}}$-spectrin for CaMKII-dependent regulation of cardiac excitability. Voltage-gated $\mathrm{Na}^{+}$channel current is required for the rapid upstroke of the cardiac AP and normal electrical conduction in myocardium (49). Furthermore, alterations in $I_{\mathrm{Na}}$ and AP prolongation contribute to congenital and acquired forms of heart disease and arrhythmia $(50,51)$. Based on our observed dysfunction of $I_{\mathrm{Na}}$ in $q v^{3 J}$ mice, we measured APs from isolated WT and $q v^{3 J}$ cardiomyocytes. As observed in other vertebrates, AP duration (APD) in WT mouse cardiomyocytes decreased with increased pacing frequency (APD adaptation, Figure 6, A and C). Notably, WT cardiomyocytes displayed a parallel reduction in $I_{N a, p}$ with increased pacing frequency (Supplemental Figure 9). Consistent with the measured decrease in $I_{N a, p}$ in $q v^{3 J}$ myocytes, $q v^{3 J}$ myocyte APs (90\% and 70\% repolarization; $\mathrm{APD}_{90}$ and $\mathrm{APD}_{75}$, respectively) were significantly shorter at all pacing frequencies compared with WT myocytes $\left(P<0.05 ; \mathrm{APD}_{50}\right.$, $P=$ NS; Figure 6, A-C and Supplemental Figure 10). Furthermore, $q v^{3 J}$ myocytes displayed diminished capacity for APD adaptation (Figure 6C). These differences, as well as differences in $I_{N a, p}$, were eliminated by mexiletine but increased by isoproterenol (Figure 4, F-I, Figure 6D, and Supplemental Figure 10). These data indicate that disruption of CaMKII signaling through the $\beta_{\mathrm{IV}}$-spectrin pathway results in aberrant cardiomyocyte electrical activity.

We used whole-animal and isolated heart electrocardiograms to test the effect of the $\beta_{\mathrm{IV}}$-spectrin/CaMKII pathway on in vivo cardiac function. $q v^{3}$ mice showed decreased QRS duration (a marker of more rapid intraventricular conduction; refs. 50, 52), QT interval, and RR interval (increased heart rate) on both surface and isolated heart electrocardiograms (Figure 6, E-I). These findings were consistent with our observations of increased $I_{\mathrm{Na}}$ availability, decreased $I_{N a, p}$, and shorter APs in $q v^{3 J}$ cardiomyocytes (Figure 4 and Figure 6, A-D).

We next investigated the effect of targeted disruption in CaMKII signaling on isoproterenol-induced cellular afterdepolarizations, which serve as important triggers for life-threatening cardiac electrical disturbances (53). At baseline, afterdepolarizations were infrequent in both WT and $q v^{3 J}$ ventricular cardiomyocytes (20\% and $10 \%$ of cells, respectively; $n=10 ; P=$ NS; Figure 7, A, $\mathrm{B}$, and $\mathrm{G})$. However, $1 \mu \mathrm{M}$ isoproterenol significantly increased afterdepolarizations in WT but not $q v^{3 J}$ cardiomyocytes (WT, 70\%, $P<0.05$ versus control; $q v^{3 J}, 10 \%, P=$ NS versus control; $n=10$ per group; Figure 7, B, E, and G). Mexiletine completely eliminated isoproterenol-induced afterdepolarizations ( $0 \%$ in WT and $q v^{3}$; $P=\mathrm{NS} ; n=5$ per group; Figure $7, \mathrm{C}, \mathrm{F}$, and G). Collectively, these data provide compelling evidence for the role of the $\beta_{\mathrm{IV}}$-spectrin/ 
A
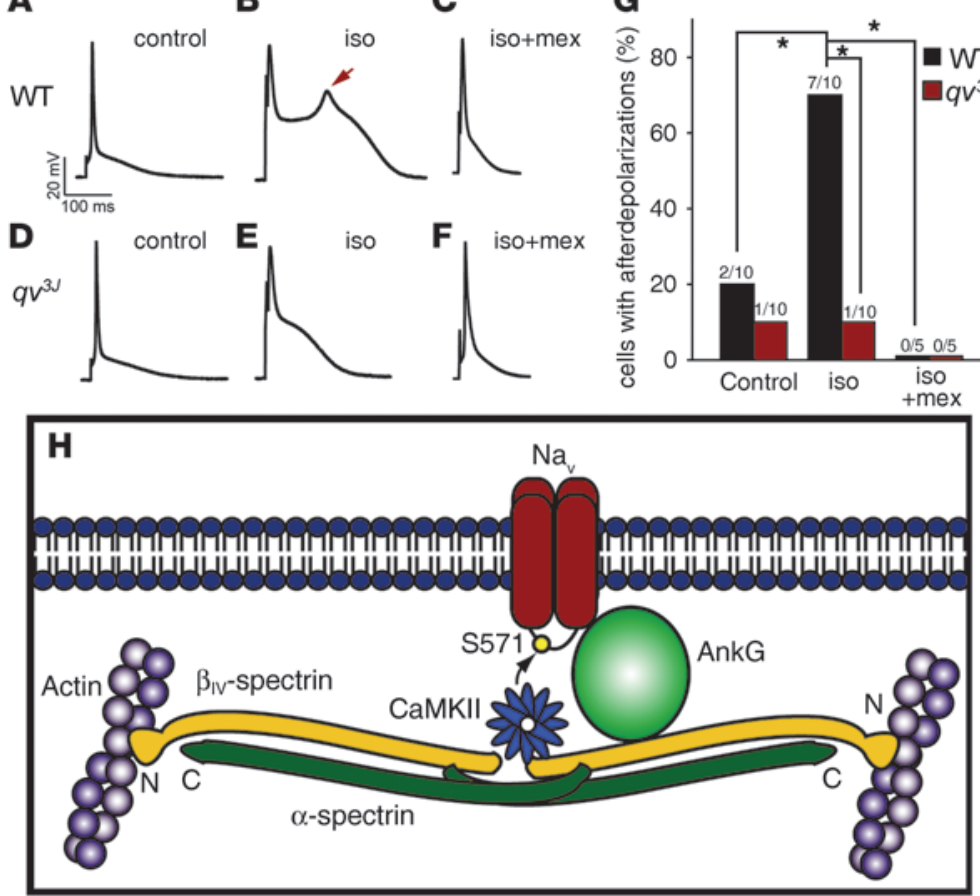

Figure 7

$\beta_{\mathrm{IV}}$-spectrin/CaMKII complex regulates afterdepolarization formation in response to isoproterenol treatment. Representative APs recorded from WT and $q v^{3 J}$ cardiomyocytes at baseline (A and $\mathbf{D})$ and following application of $1 \mu \mathrm{M}$ isoproterenol (B and E) or isoproterenol applied with $10 \mu \mathrm{M}$ mexiletine (C and $\mathbf{F}$ ). (G) Summary data showing percent cells displaying afterdepolarizations in WT and $q v^{3 J}$ at baseline ( $n=10$ per genotype) and following application of isoproterenol $(n=10$ per genotype) or isoproterenol applied with mexiletine ( $n=5$ per genotype). ${ }^{*} P<0.05$. $(\mathbf{H})$ $\beta_{\mathrm{IV}}$-spectrin-based complex targets CaMKII to effector proteins in excitable cells.

CaMKII signaling complex in normal myocyte physiology and suggest that modulation of this complex may represent a novel target to suppress persistent component of $I_{\mathrm{Na}}$ for arrhythmia treatment (Figure $7 \mathrm{H})$.

The $\beta_{I V}$-spectrin-dependent targeting pathway is conserved in excitable neurons. While implicated in membrane biogenesis and maintenance, as well as ion channel clustering in the nervous system, we believe a role for $\beta_{\mathrm{IV}}$-spectrin in neuronal signaling is unprecedented. Based on our findings from heart, we tested the requirement of $\beta_{\mathrm{IV}}$-spectrin for local CaMKII organization in brain. In cerebellar Purkinje neurons, $\beta_{\mathrm{IV}}$-spectrin was localized to AISs with ankyrin-G $(39,40,54)$ and associated with ankyrin-G in detergent-soluble cerebellar lysates (Figure 8A). In agreement with our findings from heart, CaMKII associated with $\beta_{\mathrm{IV}}$-spectrin in brain lysates (Figure $8 \mathrm{~B}$ ). Moreover, CaMKII was coexpressed with $\beta_{\mathrm{IV}}$-spectrin in Purkinje neuron AISs, but also localized to the neuronal cell body (Figure 8C). Consistent with our findings from heart, $q v^{3} J$ mice displayed aberrant targeting of CaMKII to the AIS (Figure 8C). Notably, CaMKII expression in the neuronal cell body was unaffected in $q v^{3 J}$ cerebellum. In contrast, both ankyrin-G and $\beta_{\mathrm{IV}}$-spectrin were normally localized at $q v^{3 J}$ AIS, although $\beta_{\mathrm{IV}}$-spectrin staining levels at the AIS were modestly decreased compared with WT cerebellum (Figure 8, $\mathrm{D}$ and $\mathrm{E})$. Importantly, these findings indicate that the $\beta_{\mathrm{IV}}$-spectrin pathway has evolved to target CaMKII gene products to specific membrane domains in functionally diverse excitable cells.

\section{Discussion}

Little is known about the cellular pathways that determine membrane excitability. Using a computational approach, we identified more than 30 putative CaMKII-binding proteins, including mitochondrial, nuclear, cytoskeletal, and membrane proteins. We performed comprehensive analyses that authenticated 1 candidate, $\beta_{\mathrm{IV}}$-spectrin, as a CaMKII-anchoring protein at select excitable membrane domains, including the Purkinje cell AIS and the cardiomyocyte intercalated disc. Notably, mice harboring a mutant $\beta_{\mathrm{IV}}$-spectrin lacking CaMKII binding activity showed defective membrane-specific CaMKII targeting, resulting in aberrant substrate activity, dysfunctional cellular excitability, and abnormal cardiac electrophysiology. Interestingly, our data also support the concept that modulating this complex may serve as an unexpected molecular target for arrhythmia therapy through suppression of late $I_{N a}$ (i.e., $I_{N a, j}$; refs. 55,56 ).

From bacteria to humans, regulated membrane excitability is central to life. Membrane ion flux drives salt and water balance, neurotransmitter release, myocyte contraction, and hormone secretion. Importantly, as recognized by Walter Cannon nearly a century ago (57), membrane excitability is remarkably fluid, constantly evolving to balance the relationship between an organism and its environment. Loss of ion homeostasis leads to disordered membrane excitability, which is a major factor in cardiac and neurological diseases. However, despite remarkable inroads into animal, tissue, and cellular physiology over the past century, arguably, the last major therapeutic breakthroughs in membrane excitability for human health and disease were the beta-blocker (discovered in the late 1950s; ref. 58), the ACE inhibitor (in the 1970s; ref. 59), and selective serotonin reuptake inhibitors (in the 1970s; ref. 60). Identification of new therapeutic agents to treat disorders of membrane excitability depends upon a more complete understanding of the cellular pathways regulating cell membrane excitability and organ function.

Previously identified CaMKII-binding partners have also served as direct substrates. For example, CaMKII associates with and phosphorylates the voltage-gated $\mathrm{Ca}^{2+}$ channel $\beta_{2 \mathrm{a}}$ subunit to modulate transverse-tubule L-type $\mathrm{Ca}^{2+}$ channel facilitation in cardiomyocytes (35). Similarly, direct binding of CaMKII with NR2B regulates NMDA receptor activity in vitro (61). In contrast, we postulate that $\beta_{\mathrm{IV}}$-spectrin, the CaMKII-targeting protein identified herein, will behave more analogous to AKAP proteins to organize the local signaling environment for multiple target substrates (Figure 8 and ref. 62). In fact, we predict that the $\beta_{\mathrm{IV}}$-spectrin $q v^{3 J}$ mice will serve as an excellent in vivo model to identify and/or validate other potential CaMKII substrates at the cardiac intercalated disc or neuronal AIS.

Initial mRNA studies did not identify significant levels of $\beta_{\mathrm{IV}}$-spectrin in multiple tissues including heart and pancreas (39, $45,63)$. Thus, our discovery of $\beta_{\mathrm{IV}}$-spectrin in the heart was initially surprising. However, $\beta_{\mathrm{IV}}$-spectrin has subsequently been identified at select membranes of pancreatic $\beta$ cells, where $\beta_{\mathrm{IV}}$-spectrin was also not identified by whole-tissue mRNA analysis (39). Thus, our present findings of a strategic concentration of $\beta_{\mathrm{IV}}$-spectrin at the ventricular cardiomyocyte intercalated disc are consistent with the notion that this protein pathway has evolved as a master 
A IP: $\beta_{\mathrm{IV}}$-spectrin
IB: ankyrin-G

238

$$
\begin{aligned}
& \text { - AnkG } \\
& \text { 등 혼 므므 }
\end{aligned}
$$
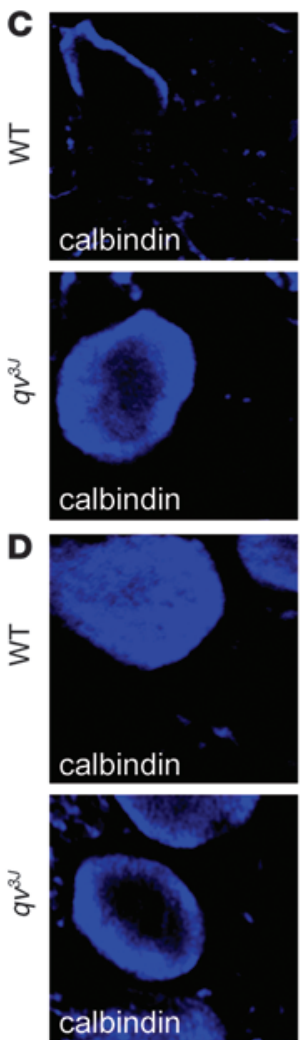

$\mathbf{E}$
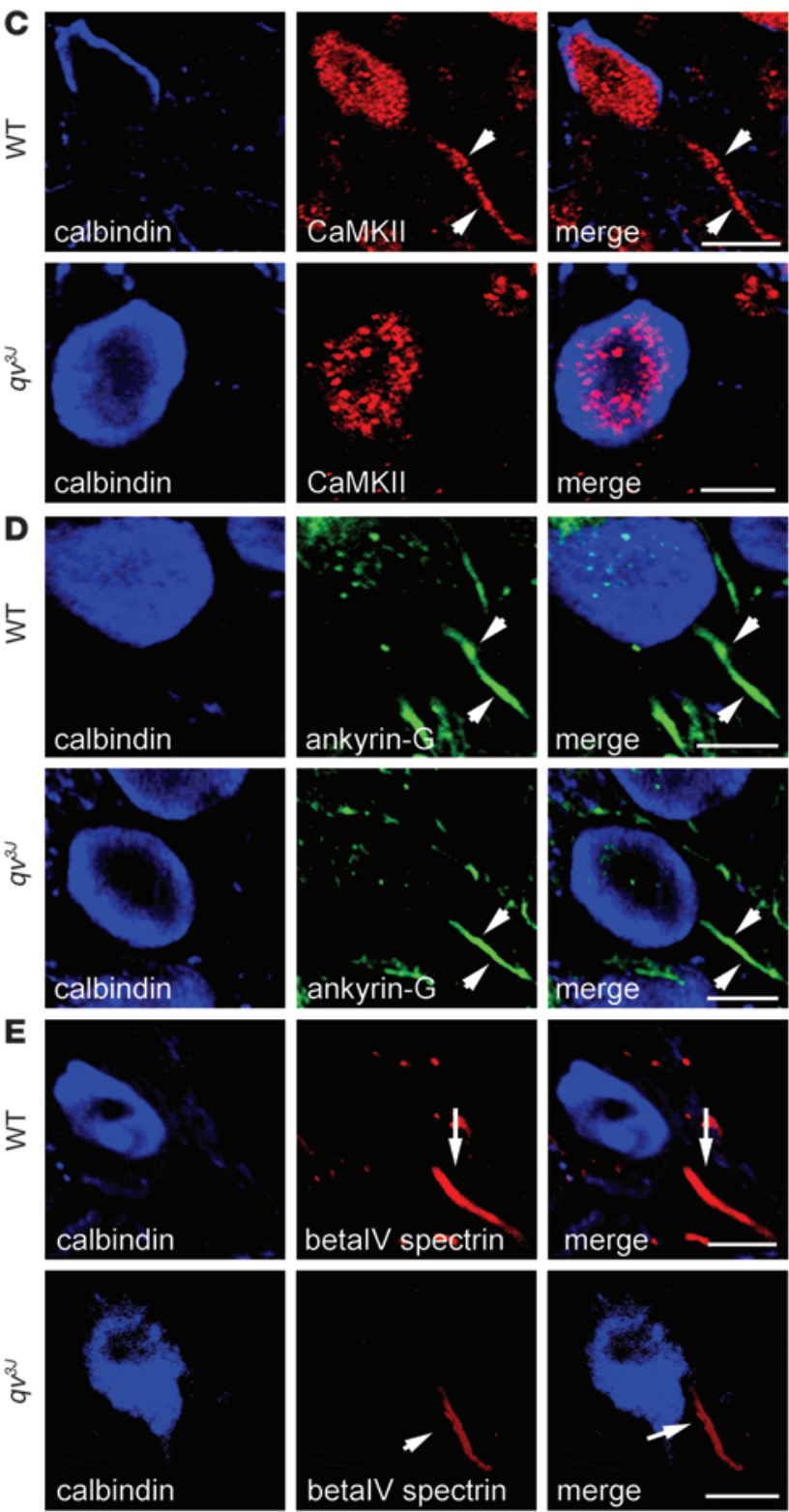

regulator of local excitable cell signaling in select cells of the brain, heart, and pancreas (albeit at significantly lower expression levels in heart compared with brain; Figure 2E). Furthermore, we predict that $\beta_{\mathrm{IV}}$-spectrin may also be localized to key membrane domains in other tissues to regulate local signaling pathways. For example, $\beta_{\mathrm{IV}}$-spectrin is localized to the neuromuscular junction, where it interacts with skeletal muscle $\mathrm{Na}^{+}$channels $\left(\mathrm{Na}_{v} 1.4\right)$ and ankyrin-G (M.N. Rasband, unpublished observations).

Our present study revealed that $\beta_{\mathrm{IV}}$-spectrin exerted spatial control over CaMKII-dependent regulation of intercalated disc voltage-gated $\mathrm{Na}^{+}$channels (targeted by $\beta_{\mathrm{IV}}$-spectrin-dependent inter-

\section{Figure 8}

$\beta_{\mathrm{IV}}$-spectrin targets CaMKII in neurons. (A and $\left.\mathbf{B}\right) \beta_{\mathrm{IV}}$-spectrin associated with both ankyrin-G and CaMKII from mouse cerebellar lysates. (C) CaMKII (red) was observed at AISs (white arrows) in WT, but not $q v^{3 J}$, cerebellum. (D) AIS integrity (shown by positive ankyrin-G staining) was not markedly affected in $q v^{3 J}$ mice. (E) $\beta_{I V}$-spectrin (red) was present at $q v^{3 J}$ mouse AISs, but at reduced levels compared with WT cerebellum. Calbindin (blue) was used to label the Purkinje cell body in C-E. Scale bars: $10 \mu \mathrm{m}(\mathbf{C}-\mathbf{E})$.

actions with ankyrin-G) and cell excitability. Independent studies from several groups demonstrate that cardiac $\mathrm{Na}_{v} 1.5$ is highly concentrated at the vertebrate myocyte intercalated disc (between $80 \%$ and $95 \%$; refs. 43, 64-66). An important future goal will be to determine the mechanisms underlying regulation of this minor nonintercalated disc (i.e., transverse-tubule and peripheral sarcolemmal) population of $\mathrm{Na}_{\mathrm{v}} 1.5$ channels.

Our findings identify the $\beta_{\mathrm{IV}}$-spectrin/CaMKII complex as an essential component for $I_{N a}$ regulation in the cardiomyocyte. In fact, $q v^{3 J}$ myocytes with targeted disruption of this complex show abnormal $I_{N a}$ inactivation properties, decreased $I_{N a, p}$, and altered cell excitability. Additionally, our findings illustrate that loss of this complex in myocytes does not affect other major cardiac ion currents, including total $\mathrm{K}^{+}$current, $I_{C a, L}$, or $I_{t o}$. Nevertheless, our findings do not rule out the possibility that other targets of the $\beta_{\mathrm{IV}}$-spectrin/CaMKII complex are important in cardiomyocytes. In fact, we predict that other resident intercalated disc proteins (including ion channels, transporters, receptors, cytoskeletal proteins, and signaling molecules) may also be modulated by the $\beta_{\mathrm{IV}}$-spectrin/CaMKII complex and contribute to observed differences in $\mathrm{APD}_{75}$ and $\mathrm{APD}_{90}$ in $q v^{3 J}$ myocytes. An important immediate future goal will be to identify additional targets for the $\beta_{\mathrm{IV}}$-spectrin/CaMKII complex, in both small and large animal models, that may yield unique insights into the relationship between CaMKII signaling and pathophysiology. For example, although both large and small animals show APD adaptation in response to changes in pacing frequency (Supplemental Figure 9 and ref. 67), $I_{N a, p}$ is an important determinant of this behavior in mice, but the potential role of $I_{N a, p}$ is less clear in larger animals, where APD adaptation is primarily attributed to $\mathrm{K}^{+}$and/or $\mathrm{Ca}^{2+}$ channel activity (reviewed in ref. 67). Thus, we anticipate that studies in different animal models will be useful for studying all aspects of the $\beta_{\mathrm{IV}}$-spectrin/ CaMKII signaling complex.

While our findings identify $\beta_{\mathrm{IV}}$-spectrin as a component of vertebrate heart, they also raise many exciting questions regarding the regulation of this complex gene and resulting gene products in heart. For example, while we have identified 2 isoforms in heart $(\Sigma 1$ and $\Sigma 6), 6 \beta_{\mathrm{IV}}$-spectrin splice forms are expressed in brain $(29,39$, $63)$. Future experiments must address how these gene products are differentially expressed throughout development and across specific cardiac excitable cells, and whether other $\beta_{\mathrm{IV} \text {-spectrin isoforms }}$ are found in heart. Moreover, while it is likely that each isoform

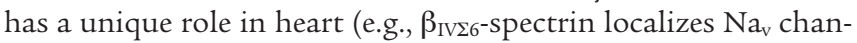
nels to AISs in neurons, ref. 28), the specific functions of $\beta_{\mathrm{IV}}$-spectrin splice variants in heart remain unknown. Based on conservation of the CaMKII- and ankyrin-G-binding motifs in $\Sigma 1$ and $\Sigma 6$ isoforms, we anticipate that both isoforms will be important for regulation of $\mathrm{Na}_{\mathrm{v}}$ channel activity and cell excitability. Finally, it is notable that we observed a small shift in the mobility of cardiac $\beta_{\mathrm{IV}}$-spectrin isoforms compared with their cerebellar $\beta_{\mathrm{IV}}$-spectrin 
counterparts (Figure 2E). While we hypothesize that this small shift may represent tissue-specific modification of residues found in both isoforms, additional experiments will be necessary to identify whether $\beta_{\mathrm{IV}}$-spectrin polypeptides display differential posttranslational modifications as well as to define how these potential modifications may differentially regulate $\beta_{\mathrm{IV}}$-spectrin function.

In addition to heart, $\beta_{\mathrm{IV}}$-spectrin also targets CaMKII to AISs in cerebellar Purkinje neurons (Figure 8). In both central and peripheral nervous systems, $\beta_{\mathrm{IV}}$-spectrin is critical for the biogenesis and maintenance of local membrane domains $(32,40,68)$. Moreover, ankyrin- $\mathrm{G}$ recruits voltage-gated $\mathrm{Na}^{+}$and $\mathrm{K}^{+}$channels to neuronal membrane domains (69). Therefore, we speculate that $\beta_{\mathrm{IV}}$-spectrin and ankyrin-G coordinate coupling between CaMKII and brain ion channels to regulate neuronal function and coordinate the cell's response to external stimuli (e.g., transmitted by increased catecholamine levels; Figure 7H). It is notable that, similar to $\beta_{\mathrm{IV}}$-spectrin $q v^{3 J}$ mice and mice lacking ankyrin-G in the cerebellum, CaMKII $\beta$-deficient mice display defects in Purkinje cell excitability and pronounced ataxia (14). Moreover, human mutations in spectrin have been identified in patients with spinocerebellar ataxia, while genome-wide association studies have linked variability in ankyrin-G expression with bipolar disorder (70). Thus, compelling data from humans and animal models strongly support the $\beta_{\mathrm{IV}}$-spectrin-based signaling platform as a nodal point for regulating excitable cell function in health and disease.

\section{Methods}

Computational analysis of putative CaMKII binding partners and in vitro binding. Novel CaMKII binding partners were identified by screening the human genome for proteins containing an 8-amino acid stretch ([LMI]-x-[RHK]$\mathrm{Q}-[\mathrm{ED}]-[\mathrm{ST}]-\mathrm{x}-[\mathrm{ED}])$ found in the CaMKII autoregulatory domain (35) using ScanProsite. Candidates were cloned from human tissue, and CaMKII-binding activity was assessed by in vitro binding assays using radiolabeled target proteins and activated CaMKII expressed in HEK cells and immunoprecipitated using monoclonal CaMKIID antibody (Santa Cruz) and TrueBlot anti-mouse Ig IP beads (eBioscience). Protein complexes were washed 5 times (50 mM Tris, pH 7.4; 1 mM EDTA; 1 mM EGTA; 500 mM $\mathrm{NaCl}$; and $0.1 \%$ Triton X-100), resuspended in SDS sample buffer, and boiled for 5 minutes. Products were separated by SDS-PAGE. To ensure equal loading, gels were stained with Coomassie Blue. $\left[{ }^{35} \mathrm{~S}\right]$-labeled in vitro translated target proteins bound to CaMKII were detected by phosphorimaging.

Animals. $q v^{3 J}$ mice and WT littermates were obtained from Jackson Laboratories. All experiments were performed in mice 8 weeks of age. The present studies were reviewed and approved by the IACUC of the University of Iowa.

Molecular biology. To generate cDNA to use for engineering fusion proteins, $\mathrm{PCR}$ primers were designed to TOPO-clone the $\mathrm{C}$-terminal region of $\beta_{\mathrm{IV}}$-spectrin from the human heart cDNA library (BD Biosciences) and the reverse transcribed cDNA from human heart tissue, based on a sequence obtained from GeneBank. To generate constructs for in vitro transcription/translation, fusion protein expression, and binding assay, cDNAs were engineered in-frame into pcDNA3. $1^{+}$(Invitrogen) and pGEX6P1 (GE Healthcare). Vectors were completely sequenced. RNA was isolated and processed for RT-PCR as described previously, using oligo-dT to prime for cDNA production (71). Primers to identify $\beta_{\mathrm{IV}}$-spectrin transcripts in heart and brain include primers directed against the $\mathrm{N}$ terminus to recognize full-length $\beta_{\mathrm{IV} \Sigma 1}$-spectrin in rat (forward, $5^{\prime}$-GGGATGGCTTTGTCCTCACCC-3'; reverse, 5'-GCCAAGAGTTCCAACTTCTCC-3'; nucleotides 271-1,226 in rat [ $\beta_{\mathrm{IV}}$-spectrin-Spnb4; XM_218364], product shown in Figure 2) as well as C-terminal primers that recognize $\beta_{\mathrm{IV \Sigma} 1}$-spectrin and $\beta_{\mathrm{IV} \Sigma} 6^{-}$spectrin in mouse ( $\beta_{\mathrm{IV}}$-spectrin-Spnb4; NM_032610) and rat (forward, 5'-CCACGATCGAGAAACTCAAGG-3'; reverse, 5' -GGTGTCCGTCGTGTCCAACG-3'; not shown).

Biochemistry and imaging. Adult heart immunoprecipitations were performed as described previously (72). The following antibodies were used for immunoblotting, immunoprecipitation, or immunostaining: antibodies against ankyrin-G (43), $\beta_{\mathrm{IV}}$-spectrin (N-terminal domain, specific domain, and C-terminal domain; provided by M. Komada, Tokyo Institute of Technology, Yokohama, Japan; or obtained from Santa Cruz or LSBio; refs. 29, 40), $\mathrm{Na}_{v} 1.5$, and

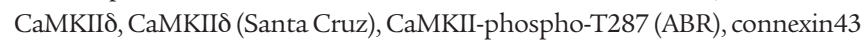
(Invitrogen), $\mathrm{N}$-cadherin (Abcam), $\beta$-catenin (BD Biosciences), actin (SigmaAldrich). Affinity-purified polyclonal antibody against phospho- $\mathrm{Na}_{\mathrm{v}} 1.5 \mathrm{~S} 571$ was developed and validated against WT and S571A mutant $\mathrm{Na}_{v} 1.5$ channels expressed in HEK cells. Adult cardiomyocytes and heart sections were isolated, immunostained, and imaged as described previously $(43,73)$.

In vitro binding. CaMKII $\delta$ was in vitro translated using the TNT Coupled Reticulocyte Lysate Systems (Promega) and labeled with [ $\left.{ }^{35} \mathrm{~S}\right]$-methionine. $\left[{ }^{35} \mathrm{~S}\right]$-labeled CaMKII $\delta$ was incubated with CTP-P, a biotinylated peptide mimicking the putative kinase-binding domain in human $\beta_{\mathrm{IV}}$-spectrin, or CTP-C, a scrambled peptide, in $500 \mu \mathrm{l}$ binding buffer $(50 \mathrm{mM}$ Tris, $\mathrm{pH}$ 7.4; $1 \mathrm{mM}$ EDTA; $1 \mathrm{mM}$ EGTA; $150 \mathrm{mM} \mathrm{NaCl}$; $0.1 \%$ Triton X-100; and 1:1,000 protease inhibitor [Sigma-Aldrich]) overnight at $4^{\circ} \mathrm{C}$. Protein complexes were washed 5 times (50 mM Tris, pH 7.4; 1 mM EDTA; 1 mM EGTA; 500 mM $\mathrm{NaCl}$; and $0.1 \%$ Triton X-100), resuspended in SDS sample buffer, and boiled for 5 minutes. Products were separated by SDS-PAGE. To ensure equal loading, gels were stained with Coomassie Blue. $\left[{ }^{35} \mathrm{~S}\right]$-labeled in vitro translated CaMKII $\delta$ that bound to the peptide was detected by phosphorimaging.

APs. APs were recorded using the perforated (amphotericin B) patchclamp technique at $36^{\circ} \mathrm{C} \pm 1{ }^{\circ} \mathrm{C}$ in Tyrode solution (bath). The pipette contained $130 \mathrm{mM}$ potassium aspartate, $10 \mathrm{mM} \mathrm{NaCl}, 10 \mathrm{mM}$ HEPES, $0.04 \mathrm{mM}$ $\mathrm{CaCl}_{2}, 2.0 \mathrm{mM}$ MgATP, $7.0 \mathrm{mM}$ phosphocreatine, $0.1 \mathrm{mM} \mathrm{NaGTP}$, and $240 \mu \mathrm{g} / \mathrm{ml}$ amphotericin $\mathrm{B}$, with the $\mathrm{pH}$ adjusted to 7.2 with $\mathrm{KOH}$. APs were evoked by brief current pulses $1.5-4 \mathrm{pA}, 0.5-1 \mathrm{~ms}$. APD was assessed as the time from the AP upstroke to $50 \%, 75 \%$, and $90 \%$ repolarization to baseline $\left(\mathrm{APD}_{50}, \mathrm{APD}_{75}\right.$, and $\mathrm{APD}_{90}$, respectively).

Electrophysiology and electrocardiograms. See Supplemental Methods and Supplemental Figure 11.

Statistics. Data are presented as mean \pm SEM. $P$ values were assessed with a paired Student's $t$ test (2-tailed) or ANOVA, as appropriate, for continuous data. The Bonferroni test was used for post-hoc testing. The null hypothesis was rejected for $P<0.05$.

\section{Acknowledgments}

We acknowledge support from the NIH (HL084583 and HL083422 to P.J. Mohler; HL079031, HL62494, and HL70250 to M.E. Anderson; NS044916 to M.N. Rasband; HL096805 to T.J. Hund), Pew Scholars Trust (to P.J. Mohler), and Fondation Leducq Award to the Alliance for Calmodulin Kinase Signaling in Heart Disease (to P.J. Mohler and M.E. Anderson). We thank M. Komada for anti$\beta_{\mathrm{IV}}$-spectrin polyclonal antibody.

Received for publication May 6, 2010, and accepted in revised form July 28, 2010.

Address correspondence to: Peter J. Mohler or Thomas J. Hund, University of Iowa Carver College of Medicine, 285 Newton Road, CBRB 2283, Iowa City, Iowa 52242, USA. Phone: 319.335.9691; Fax: 319.353.5552; E-mail: peter-mohler@uiowa.edu (P.J. Mohler). Phone: 319.384.1167; Fax: 319.353.5552; E-mail: thomas-hund@ uiowa.edu (T.J. Hund). 
1. Frankland PW, O'Brien C, Ohno M, Kirkwood A, Silva AJ. Alpha-CaMKII-dependent plasticity in the cortex is required for permanent memory. Nature. 2001;411(6835):309-313.

2. Karcher RL, et al. Cell cycle regulation of myosin-V by calcium/calmodulin-dependent protein kinase II. Science. 2001;293(5533):1317-1320.

3. Lisman J, Schulman H, Cline H. The molecular basis of CaMKII function in synaptic and behavioural memory. Nat Rev Neurosci. 2002;3(3):175-190.

4. Nutt LK, et al. Metabolic regulation of oocyte cell death through the CaMKII-mediated phosphorylation of caspase-2. Cell. 2005;123(1):89-103

5. Zhang R, et al. Calmodulin kinase II inhibition protects against structural heart disease. Nat Med. 2005;11(4):409-417.

6. Boknik P, et al. Enhanced protein phosphorylation in hypertensive hypertrophy. Cardiovasc Res. 2001;51(4):717-728.

7. Colomer JM, Mao L, Rockman HA, Means AR. Pressure overload selectively up-regulates $\mathrm{Ca} 2+$ / calmodulin-dependent protein kinase II in vivo. Mol Endocrinol. 2003;17(2):183-192.

8. Currie S, Smith GL. Enhanced phosphorylation of phospholamban and downregulation of sarco/endoplasmic reticulum Ca2+ ATPase type 2 (SERCA 2) in cardiac sarcoplasmic reticulum from rabbits with heart failure. Cardiovasc Res. 1999;41(1):135-146

9. Hagemann D, Bohlender J, Hoch B, Krause EG, Karczewski P. Expression of Ca2+/calmodulindependent protein kinase II delta-subunit isoforms in rats with hypertensive cardiac hypertrophy. Mol Cell Biochem. 2001;220(1-2):69-76.

10. Hempel P, Hoch B, Bartel S, Karczewski P. Hypertrophic phenotype of cardiac calcium/calmodulindependent protein kinase II is reversed by angiotensin converting enzyme inhibition. Basic Res Cardiol. 2002;97 suppl 1:I96-I101.

11. Hoch B, Meyer R, Hetzer R, Krause EG, Karczewski $P$. Identification and expression of delta-isoforms of the multifunctional $\mathrm{Ca} 2+/$ calmodulin-dependent protein kinase in failing and nonfailing human myocardium. Circ Res. 1999;84(6):713-721.

12. Mishra S, Sabbah HN, Jain JC, Gupta RC. Reduced $\mathrm{Ca} 2+$-calmodulin-dependent protein kinase activity and expression in LV myocardium of dogs with heart failure. Am J Physiol Heart Circ Pbysiol. 2003;284(3):H876-883.

13. Netticadan T, Temsah RM, Kawabata K, Dhalla NS. Sarcoplasmic reticulum $\mathrm{Ca}(2+) /$ Calmodulindependent protein kinase is altered in heart failure. Circ Res. 2000;86(5):596-605.

14. van Woerden GM, et al. betaCaMKII controls the direction of plasticity at parallel fiber-Purkinje cell synapses. Nat Neurosci. 2009;12(7):823-825.

15. Silva AJ, Stevens CF, Tonegawa S, Wang Y. Deficient hippocampal long-term potentiation in alpha-calcium-calmodulin kinase II mutant mice. Science. 1992;257(5067):201-206

16. Wagner S, et al. Ca2+/calmodulin-dependent protein kinase II regulates cardiac $\mathrm{Na}+$ channels. J Clin Invest. 2006:116(12):3127-3138.

17. Maier LS, Bers DM. Role of Ca2+/calmodulindependent protein kinase (CaMK) in excitationcontraction coupling in the heart. Cardiovasc Res. 2007;73(4):631-640.

18. Aiba $\mathrm{T}$, et al. $\mathrm{Na}+$ channel regulation by $\mathrm{Ca} 2+/$ calmodulin and $\mathrm{Ca} 2+/$ calmodulin-dependent protein kinase II in guinea-pig ventricular myocytes. Cardiovasc Res. 2010;85(3):454-463.

19. Bossuyt J, et al. Ca2+/calmodulin-dependent protein kinase IIdelta and protein kinase D overexpression reinforce the histone deacetylase 5 redistribution in heart failure. Circ Res. 2008;102(6):695-702

20. Passier R, et al. CaM kinase signaling induces cardiac hypertrophy and activates the MEF2 transcription factor in vivo. $J$ Clin Invest. 2000 105(10):1395-1406

21. Zhu W, Woo AY, Yang D, Cheng H, Crow MT, Xiao RP. Activation of CaMKIIdeltaC is a common intermediate of diverse death stimuliinduced heart muscle cell apoptosis. J Biol Chem. 2007;282(14):10833-10839.

22. Ramirez MT, Zhao XL, Schulman H, Brown JH. The nuclear deltaB isoform of $\mathrm{Ca} 2+/$ calmodulin-dependent protein kinase II regulates atrial natriuretic factor gene expression in ventricular myocytes. J Biol Chem. 1997;272(49):31203-31208.

23. Thiel WH, et al. Proarrhythmic Defects in Timothy Syndrome Require Calmodulin Kinase II. Circulation. 2008;118(22):2225-2234.

24. Wu Y, et al. Suppression of dynamic $\mathrm{Ca}(2+)$ transient responses to pacing in ventricular myocytes from mice with genetic calmodulin kinase II inhibition. J Mol Cell Cardiol. 2006;40(2):213-223.

25. Khoo MS, et al. Death, cardiac dysfunction, and arrhythmias are increased by calmodulin kinase II in calcineurin cardiomyopathy. Circulation. 2006;114(13):1352-1359.

26. Chelu MG, et al. Calmodulin kinase II-mediated sarcoplasmic reticulum Ca2+ leak promotes atrial fibrillation in mice. JClin Invest. 2009;119(7):1940-1951.

27. Kosaka T, Komada M, Kosaka K. Sodium channel cluster, betaIV-spectrin and ankyrinG positive "hot spots" on dendritic segments of parvalbumin-containing neurons and some other neurons in the mouse and rat main olfactory bulbs. Neurosci Res. 2008;62(3):176-186.

28. Uemoto Y, et al. Specific role of the truncated betaIV-spectrin Sigma6 in sodium channel clustering at axon initial segments and nodes of ranvier. J Biol Chem. 2007;282(9):6548-6555.

29. Komada M, Soriano P. [Beta]IV-spectrin regulates sodium channel clustering through ankyrin-G at axon initial segments and nodes of Ranvier. J Cell Biol. 2002;156(2):337-348.

30. Koticha D, et al. Neurofascin interactions play a critical role in clustering sodium channels, ankyrin G and beta IV spectrin at peripheral nodes of Ranvier. Dev Biol. 2006;293(1):1-12.

31. Dzhashiashvili Y, Zhang Y, Galinska J, Lam I, Grumet M, Salzer JL. Nodes of Ranvier and axon initial segments are ankyrin G-dependent domains that assemble by distinct mechanisms. J Cell Biol. 2007; 177(5):857-870.

32. Yang Y, Lacas-Gervais S, Morest DK, Solimena M, Rasband MN. BetaIV spectrins are essential for membrane stability and the molecular organization of nodes of Ranvier. J Neurosci. 2004;24(33):7230-7240.

33. Jenkins SM, Bennett V. Ankyrin-G coordinates assembly of the spectrin-based membrane skeleton, voltage-gated sodium channels, and L1 CAMs at Purkinje neuron initial segments. J Cell Biol. 2001;155(5):739-746.

34. Srinivasan Y, Elmer L, Davis J, Bennett V, Angelides $\mathrm{K}$. Ankyrin and spectrin associate with voltagedependent sodium channels in brain. Nature. 1988;333(6169):177-180.

35. Grueter CE, et al. L-Type $\mathrm{Ca}(2+)$ Channel Facilitation Mediated by Phosphorylation of the beta Subunit by CaMKII. Mol Cell. 2006;23(5):641-650.

36. Saurin AT, Durgan J, Cameron AJ, Faisal A, Marber MS, Parker PJ. The regulated assembly of a PKCepsilon complex controls the completion of cytokinesis. Nat Cell Biol. 2008;10(8):891-901.

37. Luders J, Patel UK, Stearns T. GCP-WD is a gammatubulin targeting factor required for centrosomal and chromatin-mediated microtubule nucleation. Nat Cell Biol. 2006;8(2):137-147.

38. Enomoto A, et al. Akt/PKB regulates actin organization and cell motility via Girdin/APE. Dev Cell. 2005;9(3):389-402.

39. Berghs $\mathrm{S}$, et al. betaIV spectrin, a new spectrin localized at axon initial segments and nodes of ranvier in the central and peripheral nervous system. J Cell Biol. 2000;151(5):985-1002.

40. Lacas-Gervais S, et al. BetaIVSigma1 spectrin stabilizes the nodes of Ranvier and axon initial segments. J Cell Biol. 2004;166(7):983-990.

41. Backs J, et al. The delta isoform of CaM kinase II is required for pathological cardiac hypertrophy and remodeling after pressure overload. Proc Natl Acad Sci U S A. 2009;106(7):2342-2347.

42. Zhou D, Lambert S, Malen PL, Carpenter S, Boland $\mathrm{LM}$, Bennett V. AnkyrinG is required for clustering of voltage-gated $\mathrm{Na}$ channels at axon initial segments and for normal action potential firing. J Cell Biol. 1998;143(5):1295-1304.

43. Mohler PJ, et al. Nav1.5 E1053K mutation causing Brugada syndrome blocks binding to ankyrin-G and expression of Nav1.5 on the surface of cardiomyocytes. Proc Natl Acad Sci U S A. 2004;101(50):17533-17538.

44. Lowe JS, et al. Voltage-gated Nav channel targeting in the heart requires an ankyrin-G dependent cellular pathway. J Cell Biol. 2008;180(1):173-186.

45. Parkinson NJ, et al. Mutant beta-spectrin 4 causes auditory and motor neuropathies in quivering mice. Nat Genet. 2001;29(1):61-65.

46. Salama G, London B. Mouse models of long QT syndrome. J Physiol. 2007;578(pt 1):43-53.

47. Wagner $\mathrm{S}$, et al. $\mathrm{Ca} /$ calmodulin kinase II differentially modulates potassium currents. Circ Arrbythm Electrophysiol. 2009;2(3):285-294

48. Li J, et al. Calmodulin kinase II inhibition shortens action potential duration by upregulation of $\mathrm{K}^{+}$ currents. Circ Res. 2006;99(10):1092-1099.

49. Papadatos GA, et al. Slowed conduction and ventricular tachycardia after targeted disruption of the cardiac sodium channel gene Scn5a. Proc Natl Acad SciU S A. 2002;99(9):6210-6215.

50. Bennett PB, Yazawa K, Makita N, George AL Jr. Molecular mechanism for an inherited cardiac arrhythmia. Nature. 1995;376(6542):683-685

51. Tan HL, et al. A sodium-channel mutation causes isolated cardiac conduction disease. Nature. 2001;409(6823):1043-1047.

52. Kanda M, et al. Electrophysiologic characteristics and implications of induced ventricular fibrillation in symptomatic patients with Brugada syndrome. J Am Coll Cardiol. 2002;39(11):1799-1805.

53. Roden DM, Lazzara R, Rosen M, Schwartz PJ, Towbin J, Vincent GM. Multiple mechanisms in the long-QT syndrome. Current knowledge, gaps, and future directions. The SADS Foundation Task Force on LQTS. Circulation. 1996;94(8):1996-2012.

54. Jenkins SM, Bennett V. Developing nodes of Ranvier are defined by ankyrin-G clustering and are independent of paranodal axoglial adhesion. Proc Natl Acad Sci U S A. 2002;99(4):2303-2308.

55. Jarecki BW, Piekarz AD, Jackson JO 2nd, Cummins TR. Human voltage-gated sodium channel mutations that cause inherited neuronal and muscle channelopathies increase resurgent sodium currents. J Clin Invest. 2010;120(1):369-378.

56. Koopmann TT, Bezzina CR, Wilde AA. Voltagegated sodium channels: action players with many faces. Ann Med. 2006;38(7):472-482.

57. Cannon WB. Bodily Changes in Pain, Hunger, Fear, and Rage: An Account of Recent Researches into the Function of Emotional Excitement. New York, New York, USA: D. Appleton. \& Co.; 1915.

58. Black JW, Stephenson JS. Pharmacology of a new adrenergic beta-receptor-blocking compound (Nethalide). Lancet. 1962;2(7251):311-314.

59. Haber E, Barger AC. Experimental and clinical studies with converting enzyme inhibitor. Prog Biochem Pharmacol. 1976;12:16-32.

60. Wong DT, Horng JS, Bymaster FP, Hauser KL, Molloy BB. A selective inhibitor of serotonin uptake: Lilly 110140, 3-(p-trifluoromethylphenoxy)-N-methyl-3-phenylpropylamine. Life Sci. 
1974;15(3):471-479.

61. Barria A, Malinow R. NMDA receptor subunit composition controls synaptic plasticity by regulating binding to CaMKII. Neuron. 2005;48(2):289-301.

62. Wong W, Scott JD. AKAP signalling complexes: focal points in space and time. Nat Rev Mol Cell Biol. 2004;5(12):959-970.

63. Tse WT, et al. A new spectrin, beta IV, has a major truncated isoform that associates with promyelocytic leukemia protein nuclear bodies and the nuclear matrix. J Biol Chem. 2001;276(26):23974-23985.

64. Allouis M, et al. 14-3-3 is a regulator of the cardiac voltage-gated sodium channel Nav1.5. Circ Res. 2006;98(12):1538-1546.

65. Maier SK, Westenbroek RE, McCormick KA, Curtis R, Scheuer T, Catterall WA. Distinct subcellular localization of different sodium channel alpha and beta subunits in single ventricular myocytes from mouse heart. Circulation. 2004;109(11):1421-1427.

66. Maier SK, et al. An unexpected requirement for brain-type sodium channels for control of heart rate in the mouse sinoatrial node. Proc Natl Acad Sci US A. 2003;100(6):3507-3512.

67. Eisner DA, Dibb KM, Trafford AW. The mechanism and significance of the slow changes of ventricular action potential duration following a change of heart rate. Exp Physiol. 2009;94(5):520-528.

68. Yang Y, Ogawa Y, Hedstrom KL, Rasband MN betaIV spectrin is recruited to axon initial segments and nodes of Ranvier by ankyrinG.J Cell Biol. 2007;176(4):509-519.

69 . Hill AS, et al. Ion channel clustering at the axon ini- tial segment and node of ranvier evolved sequentially in early chordates. PLoS Genet. 2008;4(12):e1000317.

70. Ferreira MA, et al. Collaborative genome-wide association analysis supports a role for ANK3 and CACNA1C in bipolar disorder. Nat Genet. 2008;40(9):1056-1058.

71. Gudmundsson $\mathrm{H}$, et al. EH domain proteins regulate cardiac membrane protein targeting. Circ Res. 2010;107(1):84-95.

72. Mohler PJ, Davis JQ, Bennett V. Ankyrin-B Coordinates the $\mathrm{Na} / \mathrm{K}$ ATPase, $\mathrm{Na} / \mathrm{Ca}$ Exchanger, and InsP(3) Receptor in a Cardiac T-Tubule/SR Microdomain. PLoS Biol. 2005;3(12):e423.

73. Mohler PJ, et al. Ankyrin-B mutation causes type 4 long-QT cardiac arrhythmia and sudden cardiac death. Nature. 2003;421(6923):634-639. 